\title{
EL MERCADO MUNDIAL DE VINO Y LA COMPETITIVIDAD DE LOS PAÍSES DEL HEMISFERIO SUR, 1961-2010*
}

\section{THE WORLD WINE MARKET AND THE COMPETITIVENESS OF THE SOUTHERN HEMISPHERE COUNTRIES, 1961-2010}

\author{
Francisco José Medina-Albaladejo \\ Universitat de València, València, España, <francisco.medina@uv.es> \\ José Miguel Martínez-Carrión \\ Universidad de Murcia, Murcia, España, <jcarrion@um.es> \\ Josep-Maria Ramon-Muñoz \\ Universidad de Murcia, Murcia, España, <jmramon@um.es>
}

Resumen: El mercado mundial del vino ha sufrido cambios intensos en las últimas décadas tras un fuerte incremento de la competitividad de los países exportadores del hemisferio sur. Su dinamismo y el aumento de la demanda de los nuevos países consumidores han acelerado el proceso de globalización del vino. En este contexto, analizamos la competencia mundial y los principales cambios en el comercio global de vinos desde 1961 hasta 2010. El artículo muestra la distribución relativa de las exportaciones en el Viejo y el Nuevo Mundo y examina la ventaja comparativa del comercio exterior a través del índice de ventaja comparativa revelada (VCR). Concluye mostrando la creciente competitividad del hemisferio sur en el mercado global, principalmente de Chile, desde la década de 1990, y de Argentina en la última década.

Palabras clave: globalización del vino; exportaciones vinícolas; industria vinícola mundial.

Abstract: The global wine market has undergone intense changes in recent decades after a sharp increase in the competitiveness of the new Southern Hemisphere exporters. The dynamism of the New World and increased demand for new consumer countries have accelerated the process of wine globalization. We study the global competition and the main changes in the world wine trade from 1961 to 2010. The article shows

* Este artículo ha sido elaborado en el marco de los proyectos de investigación 11992/ PHCS/09 de la Fundación Séneca, Agencia de Ciencia y Tecnología de la Región de Murcia, España, y HAR2010-20684-C02-01/02 del Ministerio de Economía y Competitividad de España. Una versión preliminar del trabajo fue presentada en el Tercer Congreso Latinoamericano de Historia Económica, Cladhe III, celebrado en San Carlos de Bariloche, Argentina, entre el 23 y el 27 de octubre de 2012. Los autores agradecen los comentarios y sugerencias recibidas en el CladHe y, especialmente, los de los evaluadores anónimos de la revista.

Am. Lat. Hist. Econ., año 21, núm. 2, mayo-agosto, 2014, pp. 40-83 
the relative distribution of exports in the Old and New World, and it examines the comparative advantage of foreign trade through the Revealed Competitive Advantage Index (RCA). It concludes showing the Southern Hemisphere growing competitiveness in the global market, mainly from Chile, from the 1990s, and Argentina in the last decade.

Key words: globalization of wine; wine exports; world wine industry.

Fecha de recepción: marzo de 2013. Fecha de aceptación: agosto de 2013.

\section{INTRODUCCIÓN}

$\mathrm{D}$ urante las últimas tres décadas se han producido cambios importantes en la industria y el comercio mundial del vino, entre los cuales destaca el incremento de la competencia internacional. El fuerte crecimiento que registró la oferta de los nuevos países productores y exportadores de vino, junto al aumento de la demanda mundial, sobre todo de los nuevos países consumidores, aceleró el proceso que viene denominándose como "globalización del vino". ${ }^{1}$ El comercio mundial muestra un fuerte dinamismo a partir de 1980 y el crecimiento de las exportaciones ha sido intenso desde entonces, al dejar de representar una sexta parte de la producción en la primera mitad de dicha década para ser más de la tercera parte en la actualidad, siendo principales protagonistas los países del hemisferio sur.

Los cambios protagonizados en la industria vinícola han sido calificados de verdadera "revolución enológica", manifiesta sobre todo en los países productores más tradicionales, y se han interpretado como una respuesta a los desafíos de la globalización del vino. Históricamente domiciliada casi por completo en los cuatro países de la Europa mediterránea (Francia, Italia, España y Portugal), la industria vinícola se ha extendido en todo el mundo y adquiere ahora renombre en Estados Unidos, Australia, Argentina, Nueva Zelanda, Sudáfrica, Chile y recientemente en China (quinta mayor productora mundial en 2012). ${ }^{2}$ Mientras la industria del Viejo Mundo se había caracterizado por el predominio de las pequeñas

\footnotetext{
${ }^{1}$ Anderson, World's, 2004; Gatti, Giraud-Héraud y Mili, Wine, 2003; Campbell y Guibert, Wine, 2007; Jenster et al., Business, 2008; Zapata, "Revolución", 2010, y Giuliani, Morrison y Rabelloti, Innovation, 2011.

${ }^{2}$ De acuerdo con los datos estadísticos publicados en el Informe sobre Vitivinicultura Mundial de la Organización Internacional de la Viña y el Vino (en adelante oIv) de 2013, el consumo de vino está aumentando rápidamente en Asia debido al fuerte crecimiento continuo en China, que ha supuesto un incremento de 67\% respecto a 2000. International Organisation of Vine And Wine, Statistical, 2013, p. 19.
} 
bodegas y cooperativas, la del Nuevo Mundo mostró una estructura organizativa muy competitiva, dominada por grandes firmas empresariales que adquirieron protagonismo en la década de 1990. Desde entonces los viejos productores pierden cuota de mercado frente a los nuevos productores, más adaptativos a las condiciones de la demanda y a los mercados más flexibles, con menos rigidez institucional. ${ }^{3}$

Las transformaciones realizadas en los viñedos y los vinos del Viejo Mundo han sido protagonizadas por un sector empresarial sumamente atomizado, basado en bodegas familiares con profusas marcas y vinos de variedades adscritas a las denominaciones de origen (en España, DO o DOC; en Francia, Appellation d'origine contrôlée, AOC; en Italia, Denominazione di origine controllata e garantita, DOCG) o bajo indicación geográfica, etiqueta VCPRD (siglas que responden a varias lenguas europeas: español, francés, italiano, portugués y catalán, conocida como "vinos de calidad producida en una región determinada"), que han caracterizado a los productores del Viejo Mundo. La importancia de la regulación institucional del vino se comprueba a través de las indicaciones geográficas que impulsó la Comisión Europea. En julio de 2011 se contabilizaron 2988 indicaciones geográficas del sector vitivinícola en el mundo, ${ }^{4}$ de las cuales 1336 son denominaciones de origen protegidas y sólo dos están fuera de la Unión Europea, una en Estados Unidos y otra en Brasil. Asimismo, destacan 956 indicaciones geográficas protegidas de las que 587 están en la Unión Europea, 153 en Africa del Sur, 72 en Australia y 57 en Chile. Existen también 696 regiones en las que se indica la procedencia del vino pero sin ningún tipo de restricción en la producción y elaboración, todas ellas localizadas en Estados Unidos.

El sistema productivo europeo se ha mostrado muy diferente al del Nuevo Mundo, el cual se ha caracterizado por marcas fuertes asociadas a gamas de varietales homogéneas bajo control de grandes firmas vitivinícolas y de la industria alimentaria, y que dominan las cadenas de producción y distribución. Los nuevos productores conquistan cuotas de mercado en países tradicionalmente poco consumidores de vino, que sin embargo acrecientan su consumo de forma sostenida y muy dinámica en algunos casos, como ocurre en los últimos tiempos en Estados Unidos, Gran Bretaña, en los países escandinavos o en los BRIC. ${ }^{5}$ El éxito del sistema de

${ }^{3}$ Heijbroek, Changing, 2007, y Hannin et al., Vigne, 2010.

${ }^{4}$ Barco y Navarro, "Factores", 2012.

${ }^{5}$ Se refiere a Brasil, Rusia, India y China, Sudáfrica se unió al grupo en 2011, con esto cambia la denominación a BRICS. En 2010 China fue el quinto consumidor y séptimo productor de vino en el mundo con una cuota aún muy pequeña en términos per cápita, de 1.15 litros anuales, casi insignificante comparada con los 45.2 litros per cápita de Francia o los 20.7 litros per cápita del Reino Unido. Sin embargo, su producción y consumo crecen a un elevado ritmo ante la in- 
producción de los nuevos productores se vio facilitado por una escasa regulación y estrategias agresivas de marketing. ${ }^{6}$

En este contexto de expansión del mercado mundial y de globalización del vino a finales del siglo XX, ¿̇mejoró la competitividad de las exportaciones vinícolas de los principales países productores latinoamericanos? Este artículo analiza el comportamiento de la industria vinícola del hemisferio sur entre 1961 y 2010 y destaca el dinamismo de las exportaciones vinícolas de los principales exportadores latinoamericanos de vinos, Chile y Argentina. Demuestra que pese al aumento de la competencia en el mercado global de vino, los vinos chilenos y argentinos llaman la atención en el mercado internacional por su relación precio-calidad y presentan ventajas comparativas muy favorables desde la década de 1990.

El trabajo consta de varias partes. Tras la introducción, la siguiente sección aborda los escenarios cambiantes del mercado global de vinos, atendiendo a la superficie de viñedo, la producción y los rendimientos del vino. Luego examina la competencia internacional en la industria vinícola mundial. Para tal fin, analiza primero la evolución de las exportaciones mundiales y de los principales bloques de países productores, con particular atención a los países latinoamericanos. Muestra la distribución relativa de las exportaciones en el Viejo y el Nuevo Mundo, y examina, finalmente, la ventaja comparativa del comercio exterior a través del índice de ventaja comparativa revelada (VCR) o índice de Balassa (1989). Acaba con la presentación de las conclusiones.

\section{LA EXPANSIÓN DE LA INDUSTRIA VINÍCOLA Y LA COMPETENCIA EN EL MERCADO MUNDIAL DE VINOS}

En esta sección se destaca el notable crecimiento de la industria vinícola y del comercio mundial de vino. El análisis se centra en la evolución de la superficie del viñedo, la producción de vino, el comercio exterior y en particular de las exportaciones. Con el fin de mostrar con detalle la dinámica de los países latinoamericanos en el contexto del Nuevo Mundo y del mercado global, hemos realizado diferentes clasificaciones siguiendo

corporación masiva de consumidores al año por la expansión de sus clases medias y adineradas elites. Jenster y Cheng, "Dragon”, 2008; Thorpe, "Globalisation”, 2009; Parcero y Villanueva, "World", 2011; Mariani, Pomarici y Boatto, "International”, 2012, y Wine Institute, World, 2010, y Capita, 2010.

${ }^{6}$ Banks y Overton, "Old”, 2010; Defrancesco, Estrella y Gennari, "Would", 2012; Gatti, Giraud-Héraud y Mili, Wine, 2003; Green, Rodríguez y Seabra, "Empresas", 2003; Anderson, World's, 2004; Remaud, Beaujanot y Couderc, "Wine”, 2006, y Jenster et al., Business, 2008. 
pautas muy parecidas a las establecidas por Anderson y Nelgen ${ }^{7}$ sobre las diferentes regiones vitivinícolas (véase cuadro 1).

Las estadísticas históricas muestran la fuerte concentración de la economía vinícola en los países europeos, mayoritariamente de la Europa meridional. Por ello, hemos mantenido el grupo EuroG4 como el más representativo del Viejo Mundo. El EuroG9 está formado por países con tradición vitivinícola pero no especialmente exportadores, aunque en los últimos tiempos realizan esfuerzos por estar presentes en los mercados de la Unión Europea. Algunos países destacados en la cultura europea del vino provienen de la Europa del este, como Hungría, Rumania y Bulgaria, ${ }^{8}$ y se han integrado al mercado mundial tras sufrir un proceso de privatización de las tierras y de los medios de producción tras la desaparición del antiguo bloque comunista.

Para el Nuevo Mundo, el grupo más representativo es el que se refiere a los principales países productores y exportadores, como Estados Unidos, Argentina, Australia, Sudáfrica, Chile y Nueva Zelanda. Sin embargo, hemos agrupado el conjunto de latinoamericanos (LAC) diferenciándolo del bloque con carácter más anglosajón (ACNSU), que incorpora a Canadá, y segregando del primero a los cuatro más dinámicos junto con México y Perú (G6LA), que también realizan importantes esfuerzos vitivinícolas en los últimos años.

\section{La reestructuración de los viñedos y la mejora de los rendimientos unitarios}

Uno de los principales cambios en el largo plazo ha sido el descenso del área de cultivo destinada a las plantaciones de viñedos, fruto de procesos de reestructuración impulsados por sucesivas políticas de regulación. Sin embargo, frente a la caída generalizada de la superficie mundial de viñedo, arrastrada por el acusado descenso mostrado en el Viejo Mundo, desde la década de 1990 sobresale el incremento de la superficie de viñedo en los países englobados en el Nuevo Mundo (véase gráfica 1). Más de 2000000 de hectáreas destinadas a viñedos han disminuido desde la década de 1960 (en total, 2180000 ha), siendo el periodo más dramático el quinquenio de 1996-2000. La disminución sostenida por los países mediterráneos (2 061000 ha) continúa hasta la actualidad, pero la magnitud de la caída de la superficie mundial queda amortiguada por el avance de los viñedos de las nuevas zonas templadas, mayoritariamente del hemisferio sur, donde

\footnotetext{
${ }^{7}$ Anderson y Nelgen, Global, 2011.

${ }^{8}$ Marks, "Competitiveness", 2011.
} 
CUADRO 1. CLASIFICACIÓN DE LOS PRINCIPALES PAÍSES PRODUCTORES EN GRANDES REGIONES VITIVINÍCOLAS

\begin{tabular}{|c|c|c|c|c|c|}
\hline \multicolumn{3}{|c|}{ Nuevo Mundo } & \multicolumn{3}{|c|}{ Viejo Mundo } \\
\hline$L A C^{\mathrm{a}}$ & $A C N S U$ & G6LA & EuroG13 & EuroG9 & EuroG4 \\
\hline Argentina & Australia & Argentina & Austria & Austria & Francia \\
\hline Bolivia & Canadá & Brasil & Bélgica & Bélgica & Italia \\
\hline Brasil & Nueva Zelanda & Chile & Bulgaria & Bulgaria & Portugal \\
\hline Chile & Sudáfrica & México & Francia & Alemania & España \\
\hline Colombia & Estados Unidos & Perú & Alemania & Grecia & \\
\hline Cuba & & Uruguay & Grecia & Hungría & \\
\hline Ecuador & & & Hungría & Luxemburgo & \\
\hline Guatemala & & & Italia & Rumania & \\
\hline Honduras & & & Luxemburgo & Suiza & \\
\hline México & & & Portugal & & \\
\hline Paraguay & & & Rumania & & \\
\hline Perú & & & España & & \\
\hline Uruguay & & & Suiza & & \\
\hline Venezuela & & & & & \\
\hline
\end{tabular}

${ }^{\text {a }}$ Latinoamérica y Caribe.

Fuente: elaboración propia.

la superficie del viñedo se ha ampliado en más de 431000 ha, lo que representa un incremento de casi 53 por ciento.

Los mayores cambios se advierten desde la década de 1980 y muestran diferentes rutas entre los nuevos países productores. Los países anglosajones experimentan un fuerte empuje del avance del viñedo desde mediados de la década de 1990, mientras el conjunto de dicha década registra un retroceso importante para los seis países más representativos de Latinoamérica (véase gráfica 2). Pero no todos los países latinoamericanos muestran similar evolución. En el grupo de los que reducen la superficie de viñedos, Argentina es el país que más disminuye su área de cultivo, junto con Uruguay y México. Entre los ganadores sobresale Chile, junto con los países anglosajones: Nueva Zelanda, Sudáfrica y Australia.

El caso de Argentina requiere atención dada la dimensión de sus viñedos y el crecimiento de su industria vinícola desde comienzos del siglo $\mathrm{Xx},{ }^{9}$ trayectoria que se diferencia del resto de los países americanos, con la

${ }^{9}$ Mateu y Stein, Vino, 2008, y Simpson, Creating, 2011. 


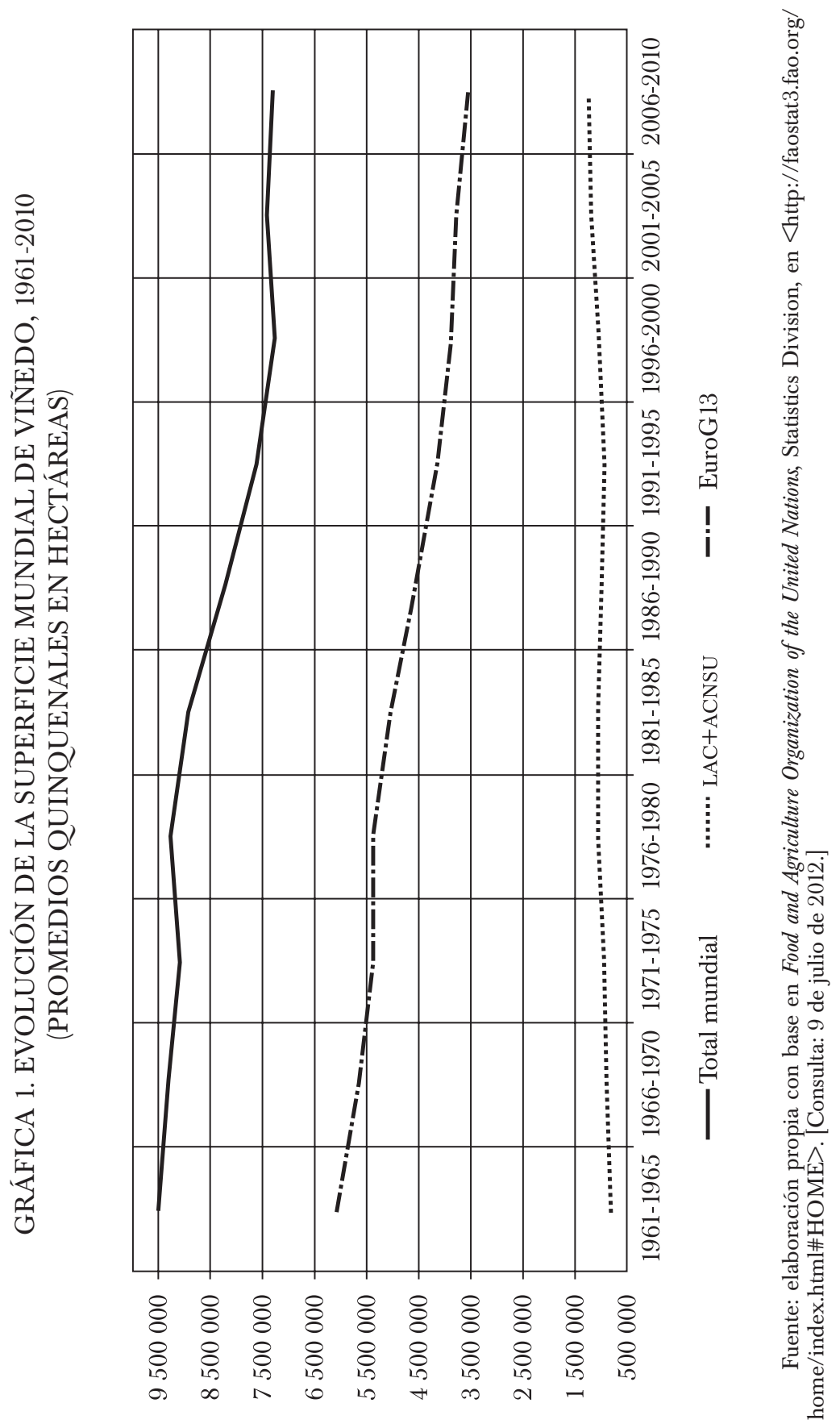




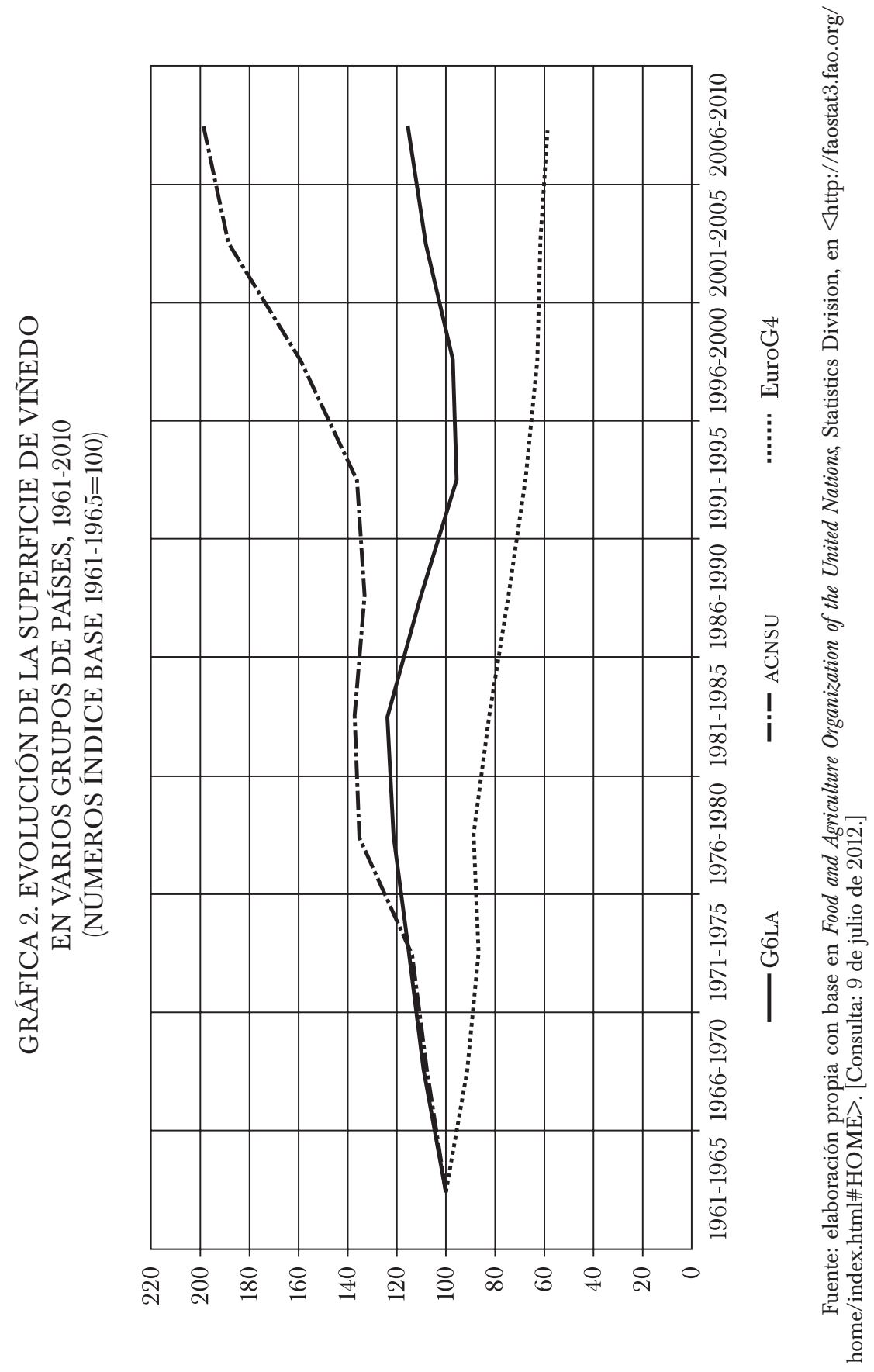


salvedad de Estados Unidos..$^{10}$ En las décadas de 1960 y 1970 la superficie argentina de viñedo creció a un ritmo intenso, pasó de ocupar 255000 ha en 1961-1964 a más de 355000 ha en 1975-1979, las cuales representaban $3.5 \%$ de la superficie mundial y más de la mitad de los viñedos latinoamericanos. La coyuntura era relativamente favorable, tanto a escala macroeconómica como internacional, con alto crecimiento económico, aumento de los ingresos y del consumo per cápita. Pese a los esfuerzos de regulación tras la creación del Instituto Nacional de Vitivinicultura en 1959, el "modelo de vino de mesa para el mercado interno" siguió formando parte del crecimiento de la industria vinícola argentina al cabo de un siglo. ${ }^{11} \mathrm{La}$ principal consecuencia de dicho modelo que primaba la cantidad más que la calidad fue un desorbitado incremento de la oferta apoyado en variedades de alto rendimiento y baja calidad enológica, lo que provocó graves desequilibrios en los mercados. Para atajar la situación, ya en la década de 1970 se tomaron algunas medidas tendentes a controlar las plantaciones y la calidad de vinos, sobre todo en las principales regiones especializadas, Mendoza y San Juan; sin embargo, hasta la Ley de 1982 no se reconoce oficialmente la crisis de sobreoferta y la necesidad de diversificar el uso de la uva, promover las exportaciones y mejorar las varietales. La década de 1980 registra una drástica reestructuración, la superficie de viñedo argentino se redujo 141000 ha entre 1977 y 1991, pasó de 350680 a 201113 hectáreas en ambas fechas. Las mayores pérdidas se registraron en superficies de uvas malbec, que pasaron de 72000 a sólo 10000 ha entre 1978 y 1990 principalmente en Mendoza. ${ }^{12}$ Desde comienzos de la década de 1990 se produce un proceso de modernización productiva que tendió a favorecer la exportación de vinos de calidad y afectó sobre todo a las bodegas radicadas en Mendoza. El fenómeno de reestructuración no pudo generalizarse a escala nacional, provocó un "dualismo productivo" entre las firmas vitivinícolas según su tamaño e integración en los mercados, y tendió a la creación de modelos de producción mucho más flexibles. ${ }^{13}$

En el Viejo Mundo, salvo Alemania que registra avances importantes en la superficie de viñedos, los principales países productores retroceden su área de cultivo por las políticas de reestructuración impuestas por la Unión Europea también desde la década de 1980. La contracción del viñedo es especialmente reseñable en el caso de España en los años previos a la entrada en la Comunidad Económica Europea en 1986, y sobre todo después. Bruselas impuso un ajuste brutal a través de la Organización Común

\footnotetext{
${ }^{10}$ Simpson, Creating, 2011.

${ }^{11}$ Perone, Identidad, 1985.

${ }^{12}$ Gennari, Estrella y Santoni, Wine, 2013.

${ }^{13}$ Bocco y Dubbini, "Reestructuración", 2011, pp. 76-79.
} 
del Mercado de Vino (en adelante OCM) en 1987, que eliminó del cultivo más de 456000 ha de viñedos entre 1980 y 2003. ${ }^{14}$ La reglamentación y normativa europea fomentó la producción de vinos de calidad, restringió los caldos corrientes, incentivó los subsidios a los arranques de los plantíos y fomentó la destilación obligatoria, método utilizado para la eliminación de excedentes en todo el marco de la Unión. El objetivo fue eliminar los viñedos poco eficientes, ajustar la oferta a la demanda y primar la producción de aquellos vinos de mayor calidad.

Entre los viejos productores, los cambios en la superficie de viñedo se vieron impulsados principalmente por la aplicación de los nuevos reglamentos comunitarios y las políticas agrarias de la Unión Europea ${ }^{15}$ que regularon las subvenciones y controlaron la sobreproducción en los viñedos, al menos desde finales de la década de 1970. También fue decisiva la reforma de la OCM que afectó asimismo la distribución de los nuevos derechos de plantación. Entre los nuevos productores, las estrategias fueron diversas. Australia reguló su oferta en función de las exportaciones, mejorando la relación de precios unitarios y de beneficios para los productores. En Argentina, la gran excedentaria de vinos de poca calidad, durante la década de 1990 entraron en vigor desregulaciones económicas que limitaron la intervención del gobierno en los mercados, eliminaron barreras a la competencia y restringieron la función del Instituto Nacional de Vitivinicultura a simples controles e inspecciones. Además se privatizaron numerosas bodegas públicas de las principales zonas productivas (Mendoza y San Juan), que pasaron bajo control de los productores que se organizaron en poderosas cooperativas vitivinícolas. Un caso ejemplar fue la temprana privatización de Bodegas y Viñedos Giol, empresa pública mendocina que pasó a formar parte de una gran cooperativa de segundo grado, la Federación de Cooperativas Vitivinícolas Argentinas. El proceso comenzó a gestarse hacia 1987 y se formalizó en $1990 .{ }^{16}$ También fueron decisivas en muchos casos las políticas monetarias que afectaron a los tipos de cambio y, no menos importantes, las condiciones del mercado de consumo y los cambios de la demanda que favorecieron la orientación hacia vinos de calidad.

\footnotetext{
${ }^{14}$ Martínez-Carrión y Medina-Albaladejo, "Change”, 2010, y "Transformaciones”, 2011, p. 236.

${ }^{15}$ Sobre la influencia de las políticas agrarias de la Unión Europea en las políticas agroalimentarias de Latinoamérica, véase Segrelles, "Política", 2012.

${ }^{16}$ En 1990 agrupa 25 cooperativas de primer orden y casi 2000 productores; en 2005 la Federación de Cooperativas Vitivinícolas Argentinas agrupa 32 cooperativas vitivinícolas primarias, con más de 5000 productores, y alcanza una participación en el mercado interno cercana a 16\%, véase Fabre, "Privatización", 2005.
} 
Uno de los aspectos relevantes que afectaron a los cambios en la superficie de viñedos ha sido la comercialización de nuevos tipos de vinos provenientes de monovarietales de los países del Nuevo Mundo. La producción de estas monovarietales -en su mayoría de origen francés- condicionó los rendimientos unitarios y la producción. En este sentido, se produjo una mejora notable de los rendimientos vitivinícolas en el mundo, impulsada principalmente por el incremento de los rendimientos en los viñedos del Nuevo Mundo desde la década de 1980 (véase gráfica 3). La década de 1990 registró un incremento extraordinario de los rendimientos unitarios principalmente en los países latinoamericanos (G6LA); de 1996 a 2000 eran 30\% más altos como promedio respecto al quinquenio de 1976-1980.

Del grupo de países del hemisferio sur destacan Sudáfrica y Nueva Zelanda, a los que se suman Canadá y Estados Unidos por parte de los nuevos países del templado hemisferio norte. Brasil y Uruguay figuran entre los países vitivinícolas con mayores tasas de crecimiento en los rendimientos, a gran distancia de Chile, que muestra un ritmo similar al de los países anglosajones. Además del fuerte crecimiento en la producción de uva por hectárea observado en los nuevos países, destaca la importancia del volumen cosechado por hectárea en Brasil, México, Chile y Argentina, además de Sudáfrica. En suma, los países productores del Nuevo Mundo exhibieron mayores rendimientos unitarios, además de un notable incremento desde comienzos de la década de 1980. Ello ha abierto una brecha entre la capacidad productiva cosechada entre viejos y nuevos productores, que supone una mayor capacidad para la producción de vino en el Nuevo Mundo, y aun entre los principales países productores latinoamericanos.

Que la mejora de los rendimientos y la mayor capacidad productiva se produjera en plena escalada del comercio internacional de vino pudo estimular el enorme flujo de capitales hacia los viñedos del Nuevo Mundo. No en vano, las grandes empresas europeas realizaron importantes inversiones a partir de la década de 1990, favoreciendo así un mayor grado de concentración empresarial. El tamaño de las empresas facilitó además un mejor entendimiento con las grandes cadenas de distribución, capaces de suministrar las cantidades requeridas, frente a la incapacidad de atender a los mercados de demanda de la mayoría de las pequeñas y medianas empresas europeas. 


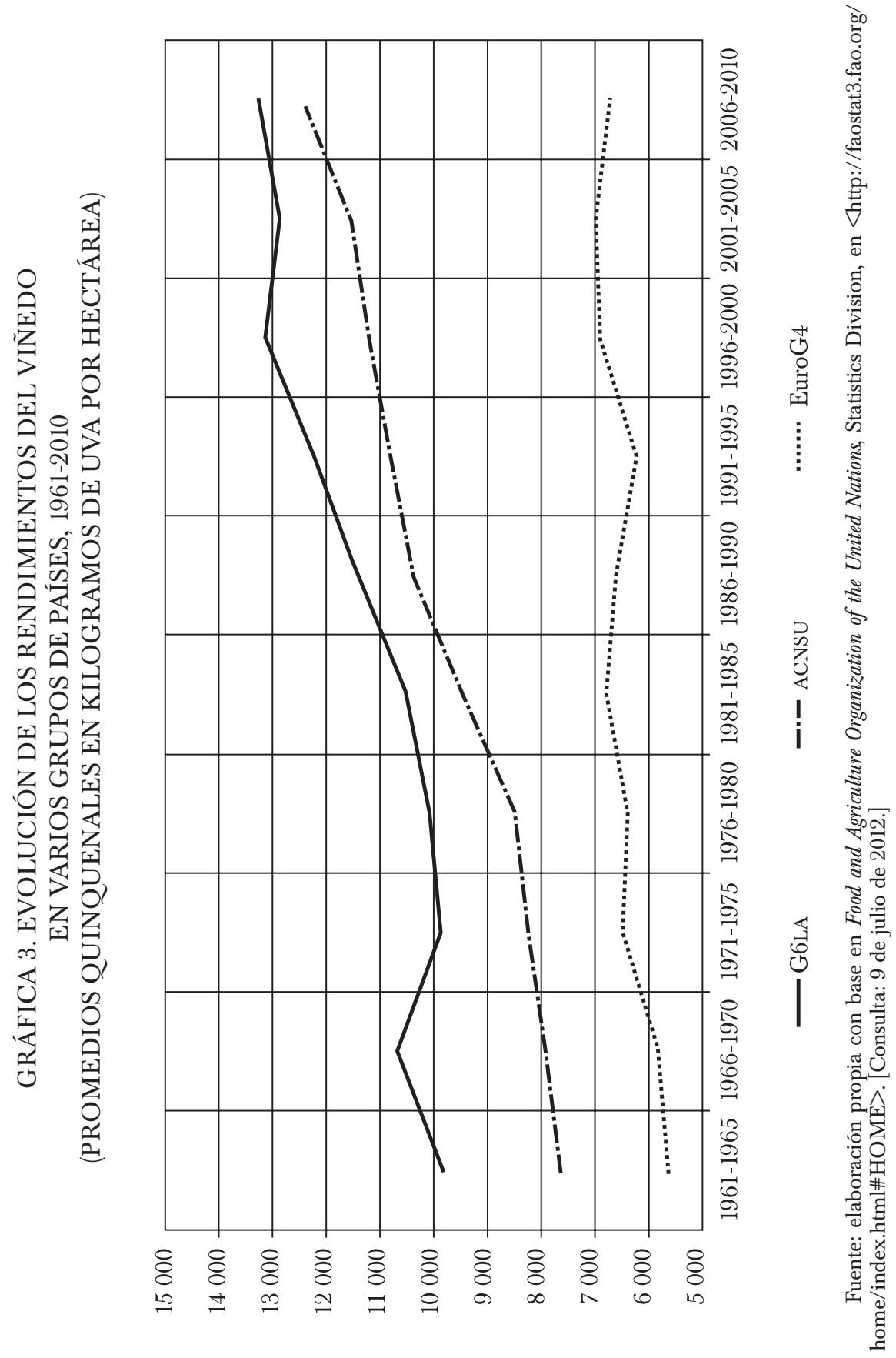




\section{Tendencias de la producción de vino}

La evolución de la oferta mundial de vino atravesó distintas coyunturas: tras el incremento registrado entre mediados de la década de 1960 y comienzos de la de 1980, disminuyó desde entonces hasta comienzos de los años noventa y se estabilizó posteriormente. La caída ha sido sensiblemente menor que la de la superficie de cultivo, por la mejora de los rendimientos. Sin embargo, las tendencias son muy divergentes según los bloques de países. El Viejo Mundo muestra una caída sostenida en las últimas tres décadas aunque repuntó algo a finales de los años noventa. En cambio, el Nuevo Mundo registra un notable crecimiento sólo interrumpido a comienzos de los noventa, con un incremento significativo entre los países anglosajones del hemisferio sur. Así, como observamos con la superficie de viñedos, los países del Nuevo Mundo ganaron cuota frente a los europeos (véanse gráficas 4 y 5).

El aumento de los rendimientos medios del vino por hectárea fue importante y casi sostenido a escala mundial, con tres periodos de fuerte empuje: a comienzos de la década de 1970, a finales de la de 1980 y finales de la de 1990. En la primera fase el avance más decisivo fue para los nuevos países productores, y en las últimas décadas es notorio en los países tradicionales, si tenemos en cuenta la estricta regulación a que se someten los sistemas de vinificación en las denominaciones de origen. Desde 1976 hasta 1980 se advierten tendencias divergentes en los rendimientos cosechados entre los productores del Nuevo Mundo. Hasta entonces las mejoras, más o menos intensas, eran generalizadas. Entre 1961-1965 y 19761980, el incremento de los rendimientos medios en el grupo anglosajón, ACNSU, fue de 52\%; el del eurogrupo de los cuatro fue 28\% y el de los principales productores latinoamericanos (G6LA) fue sólo de 6\%. En las tres décadas siguientes, 1981-2010, los productores anglosajones avanzan $15 \%$, los cuatro europeos $13 \%$, mientras que los latinoamericanos disminuyen $6 \%$. Las ventajas son intensas en los países anglosajones. Las mejoras de los rendimientos inducidas por cambios tecnológicos y enológicos en algunos países amortiguaron la caída de la oferta de vino originada en los procesos de reestructuración e hicieron posible que la crisis en algunas regiones productoras no fuera más acentuada, como en el caso de España. ${ }^{17}$ No obstante, pese a las mejoras, destaca la capacidad de los nuevos productores como revela la enorme ventaja en rendimientos unitarios de los países anglosajones (véase gráfica 6). El desafío para los productores latinoamericanos del hemisferio sur es decisivo.

\footnotetext{
${ }^{17}$ Martínez-Carrión y Medina-Albaladejo, “Competitividad”, 2013.
} 


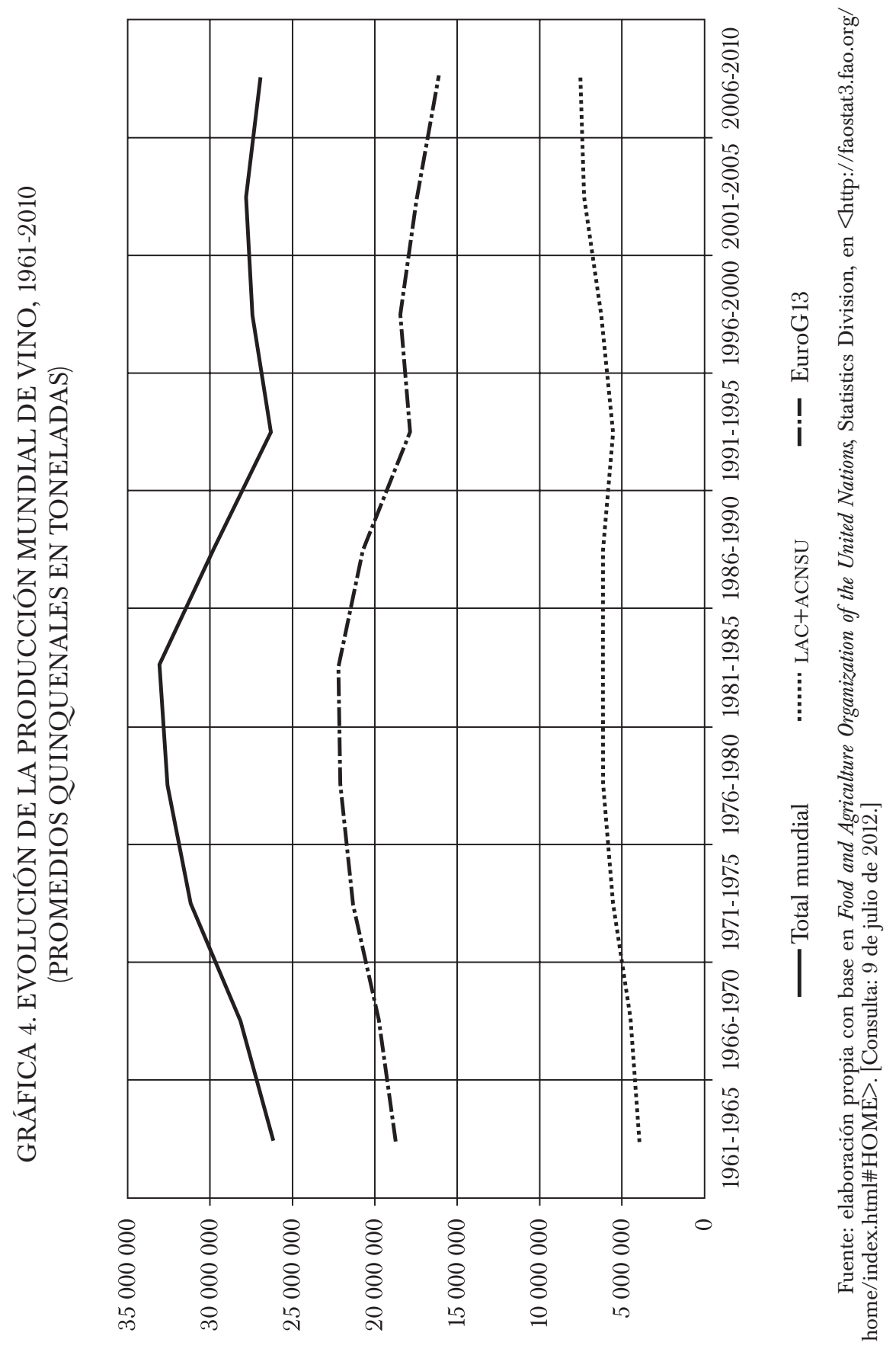




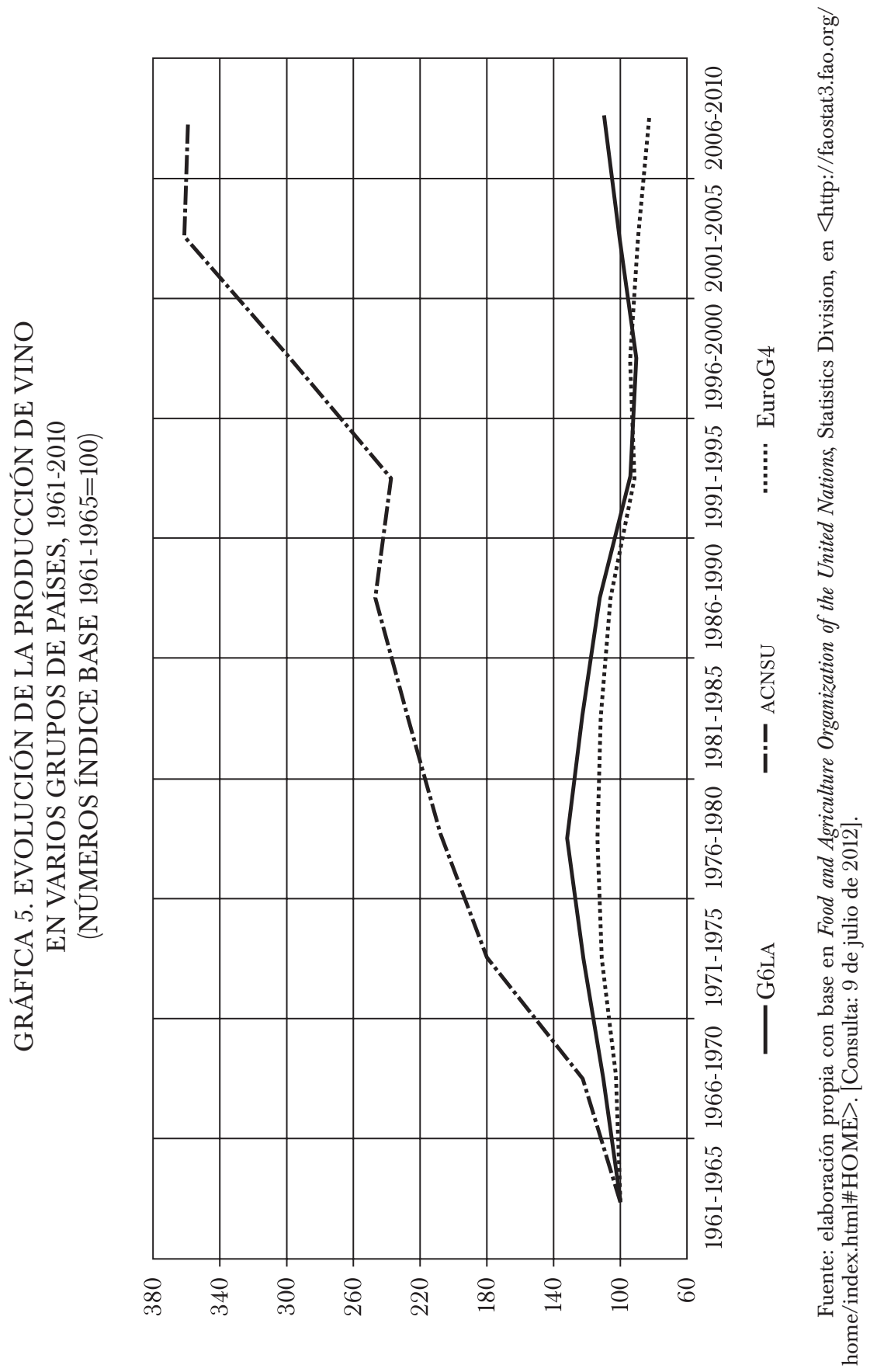




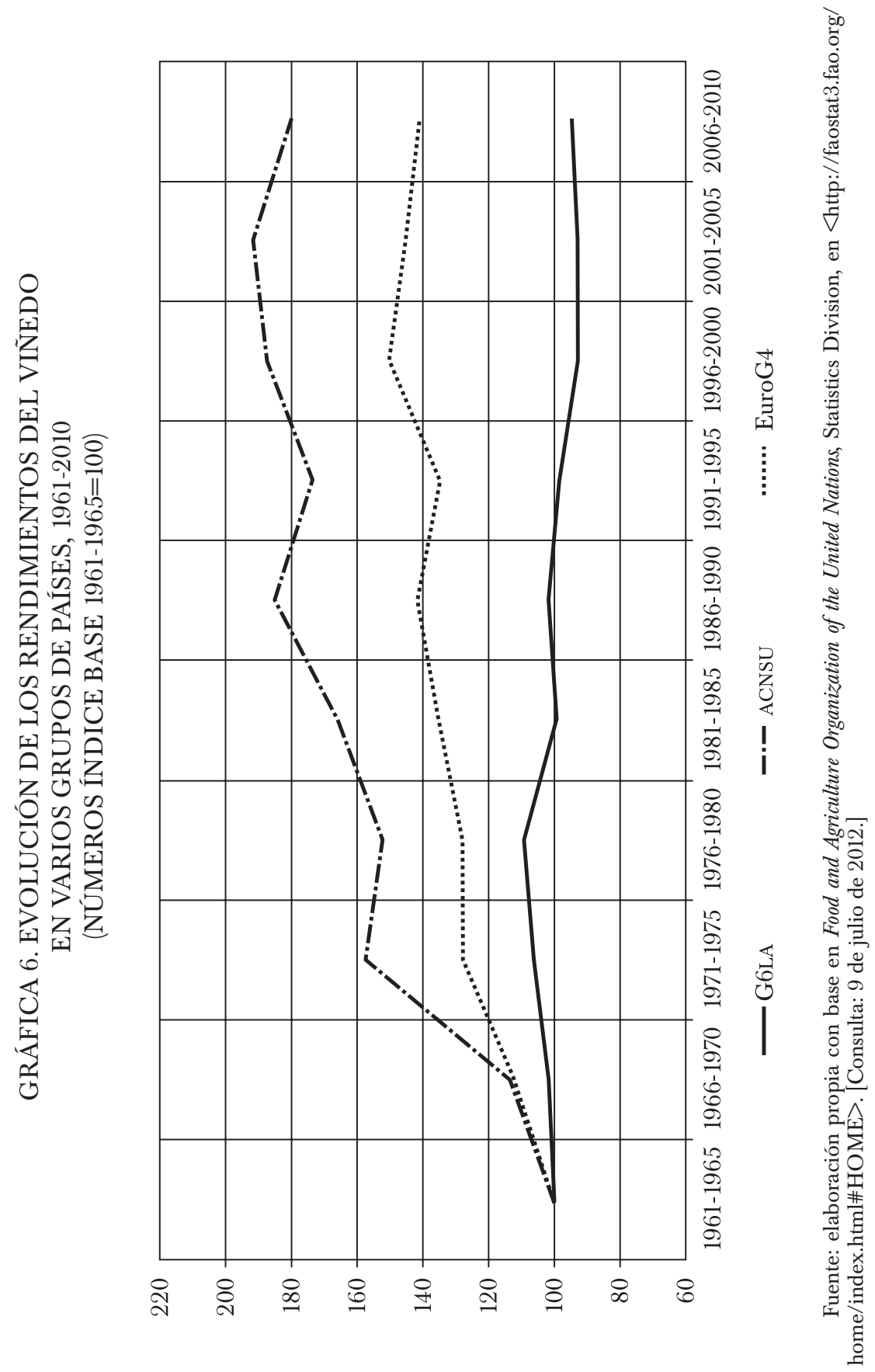


Las transformaciones de la economía mundial han modificado la posición relativa de los nuevos productores de vino. Sudáfrica, Australia y Chile han pasado a ser importantes zonas de producción desde 1990. El rápido crecimiento económico de las últimas décadas del siglo XX ha dado lugar a la aparición de nuevas clases de consumidores que han influido en los patrones de consumo y en buena medida en la producción local, difundiéndose nuevas variedades e implantándose monovarietales de alto rendimiento en la mayoría de los casos. En el Nuevo Mundo, Argentina y Estados Unidos lideran el ranking en la oferta de vinos, como lo hicieran hace un siglo y sobre todo desde mediados del siglo $\mathrm{XX}^{18}$ (véase gráfica 7 ). Argentina figuró como primer país productor hasta la segunda mitad de la década de 1980, cuando fue rebasada por Estados Unidos. Pese a la drástica reestructuración a que se vio sometida en esos años, Argentina es hoy por hoy el mayor productor latinoamericano. El enorme potencial argentino se encuentra en la fuerte tradición consumidora de vino desde finales del siglo XIX y comienzos del XX, un país forjado por migrantes provenientes de la Europa mediterránea, Italia y España, principalmente.$^{19}$ Mendoza constituyó durante mucho tiempo la principal región productora del país.

El creciente empuje de la producción de vino en Estados Unidos se debe a la expansión registrada en el estado de California. El enorme potencial del mercado interno estadunidense explica asimismo el fuerte incremento desde la década de 1970 y en fechas más recientes. Algunos estudios desvelan el papel de las ciudades y de los principales centros urbanos dentro del enorme mercado interno de Estados Unidos y el de las mujeres como segmento dentro de los nuevos consumidores con mayor potencial de crecimiento. ${ }^{20} \mathrm{El}$ salto de la oferta estadunidense en el mercado global de vinos ha sido destacable, al pasar de 2.8 a $9.3 \%$ del total mundial entre 1961-1965 y 2005-2009, y liderar el grupo de los nuevos países productores. En cambio, el otro gran productor americano, Argentina, disminuye su producción desde la década de 1980 y pasa de 7.7 a $5.3 \%$ en el mismo tramo. Después de Argentina, destacan Australia, Sudáfrica y Chile.

\section{El consumo y el crecimiento de las exportaciones mundiales}

Uno de los mayores desafíos que afronta la industria vinícola mundial ha sido el cambio registrado en las pautas de consumo. En las décadas finales

${ }^{18}$ Anderson y Nelgen, Global, 2011, p. 464.

${ }^{19}$ Algunos estudios recientes muestran la dimensión del proceso, Simpson, "Factor", 2011, y Creating, 2011; Mateu y Stein, Vino, 2008; Richard-Jorba et al., Región, 2006, y Cerdá, Condiciones, 2011.

${ }^{20}$ Canning y Pérez, "Economic", 2008. 


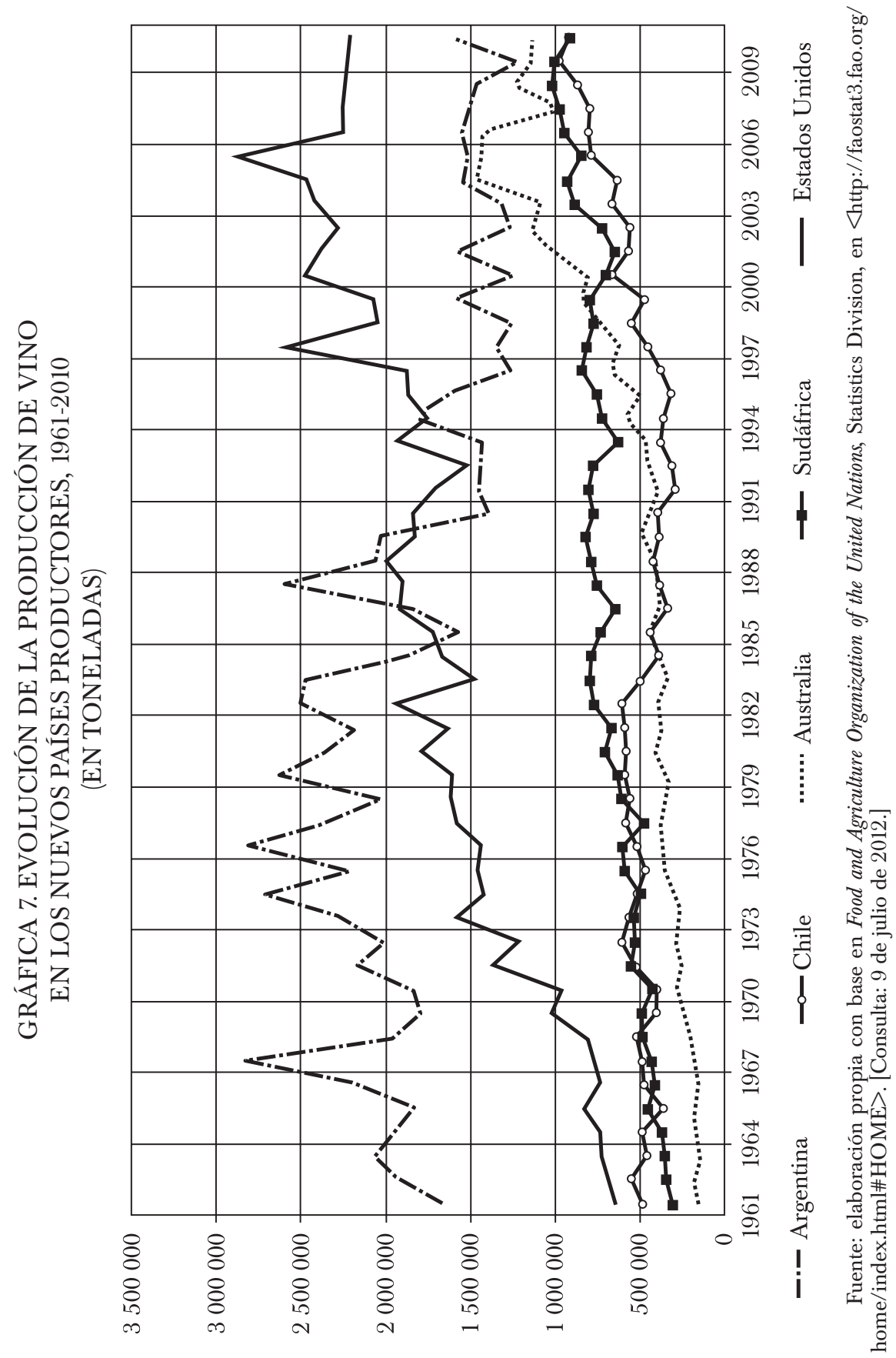


del siglo Xx el consumo mundial de vino ha descendido de forma muy acusada. En las últimas cuatro décadas el consumo mundial de vino disminuyó 15.6\%, pasó de 280300000 hectolitros en 1971-1975 a 239800000 en 1986-1990 y a 236300000 en 2010, aunque en la primera década del siglo XXI se atisba una recuperación como consecuencia de la entrada de nuevos consumidores procedentes de los zonas del planeta con menor tradición vitivinícola y de regiones emergentes. ${ }^{21}$

En términos per cápita, el consumo mundial ha pasado de 7.2 litros en 1961-1964 a cinco litros en 1985-1989 y a 3.4 litros en 2005-2009. Los países del Viejo Mundo registran las mayores pérdidas dada su fuerte tradición de consumo desde finales del siglo XIX. ${ }^{22}$ Francia pasó de 118.2 litros en 1965 a 39.4 litros en 2009; Italia, de 111.3 a 43.4 litros, y España de 59.2 a 18.4 litros, respectivamente. En el Nuevo Mundo, la evolución ha seguido un curso diferente según la tradición vitivinícola: Argentina y Chile muestran un acusado descenso del consumo de vino en un proceso similar al registrado en los países mediterráneos. El primero pasa de 84.7 litros en 1965-1969 a 27.5 litros en 2005-2009. El segundo pasa de 48.3 a 15.2 litros en el mismo periodo. El caso de Uruguay llama la atención por la estabilidad de su consumo en torno a niveles relativamente moderados, estimados en 27.3 y 25.4 litros para ambas fechas. Por el contrario, allá donde el consumo ha sido históricamente bajo, como en los países de tradición anglosajona, el consumo ha sido creciente. Australia pasa de 6.7 a 22.8 litros en el mismo tramo y Estados Unidos de 3.9 a 8.7 litros. $^{23}$ Sudáfrica, en cambio, apenas registra modificaciones en su consumo que tradicionalmente ha sido relativamente bajo: 8.9 litros en 1965-1969 y 7.1 litros en 2005-2009, hecho que puede estar relacionado con el fuerte predominio de etnias con hábitos culturales diferentes en el consumo de bebidas. Agua, zumos, refrescos y cerveza se conforman como principales bebidas sustitutivas en países de cultura vinícola pero, en conjunto, también registran un fuerte crecimiento de su ingesta en países de escasa tradición de consumo de bebidas alcohólicas. El viraje hacia la cerveza en las zonas de tradición vitivinícola ha sido mayor, ocurriendo lo contrario en los nuevos países, principalmente anglosajones. Así, los países mediterráneos, España, Italia y, sobre todo, Portugal, desplazan sus preferencias hacia la cerveza, cuyo consumo incluso se cuadruplica en términos per cápita entre 1961-1964 y 2005-2009. Entre los anglosajones, Australia y Nueva

\footnotetext{
${ }^{21}$ Datos de la Organización Internacional de la Viña y el Vino, en $<$ http://www.oiv.int/oiv/ info/esstatistiquessecteurvitivinicole>. [Consulta: 9 de julio de 2012.]

${ }^{22}$ Morilla-Critz, "Cambios", 2001; Pan-Montojo, "Vitiviniculturas", 2009, y Anderson y Nelgen, Global, 2011.

${ }^{23}$ Datos de la Organización Internacional de la Viña y el Vino, en $<$ http://www.oiv.int/oiv/ info/esstatistiquessecteurvitivinicole>. [Consulta: 9 de julio de 2012.]
} 
Zelanda disminuyen el consumo de cerveza, mientras que Canadá y Estados Unidos permanecen estabilizados. En la región latinoamericana, casi todos incrementan el consumo de cerveza, precisamente en los de cultura vitivinícola, y de manera significativa en Brasil y Argentina. ${ }^{24}$

En resumen, los países poco o menos consumidores con mayor desarrollo económico han acrecentado su consumo hasta alcanzar los promedios de los países de mayor tradición vitivinícola. Como ejemplo, en el mismo periodo Alemania pasó de 15.7 litros per cápita a más de 25 litros, y Suecia de 4.3 a casi 22 litros per cápita. La caída del consumo se hace efectiva desde la década de 1970, lo que algunos autores denominan como "revolución del consumo"; al dejar de ser el vino una bebida de consumo cotidiano pasa a ser de consumo ocasional en los países de la Europa meridional. ${ }^{25}$

Desde la década de 1980 se registra una tendencia a la homogeneización en las preferencias de los consumidores en casi todas partes. La globalización del vino ha supuesto un desplazamiento de la demanda desde los vinos corrientes y distribuidos a granel, hacia los vinos de calidad, de menor graduación, frescos, jóvenes y con una adecuada presentación que privilegia en ocasiones la diferenciación del producto, ya sea por la marca, la indicación geográfica y la denominación de origen en algunos casos, la variedad en otros, y aun en los últimos tiempos por la relación calidadprecio. En las dos últimas décadas el vino ha dejado de ser un artículo de primera necesidad para convertirse en un artículo de consumo esporádico, y debido a su componente heterogéneo permite una diferenciación cualitativa y el aumento de su valor añadido en el mercado. ${ }^{26}$

Los cambios en la estructura de la oferta y de la demanda han afectado la evolución y la composición del comercio global de vino. En primer lugar, cabe destacar que las exportaciones mundiales aumentaron significativamente en las últimas cuatro décadas, de 2610000 toneladas en 1961-1965 pasaron a 4310000 en 1986-1890 y a 9800000 en 2010 (véase gráfica 8). El incremento registrado a lo largo del periodo ha supuesto una mejora de la participación del comercio exterior en la producción total mundial, que ha pasado de $9.96 \%$ en $1961-1965$ a $18.76 \%$ en $1991-1995$ y a $33.25 \%$ en 2006-2010. De manera que, ante la caída del consumo que se registra sobre todo entre los países productores más tradicionales, el crecimiento de las exportaciones a escala mundial ha mejorado el balance

${ }^{24}$ Anderson y Nelgen, Global, 2011, p. 159.

${ }^{25}$ Pan-Montojo, "Vitiviniculturas", 2009.

${ }^{26}$ Es frecuente en los últimos años estudios que aplican la metodología de precios hedónicos al mercado de vinos. Para un trabajo pionero, véase Oczkowski, "Hedonic", 1994. Para los vinos del Nuevo Mundo, recientemente véase Estrella, Defrancesco y Gennari, "Wine”, 2012. 


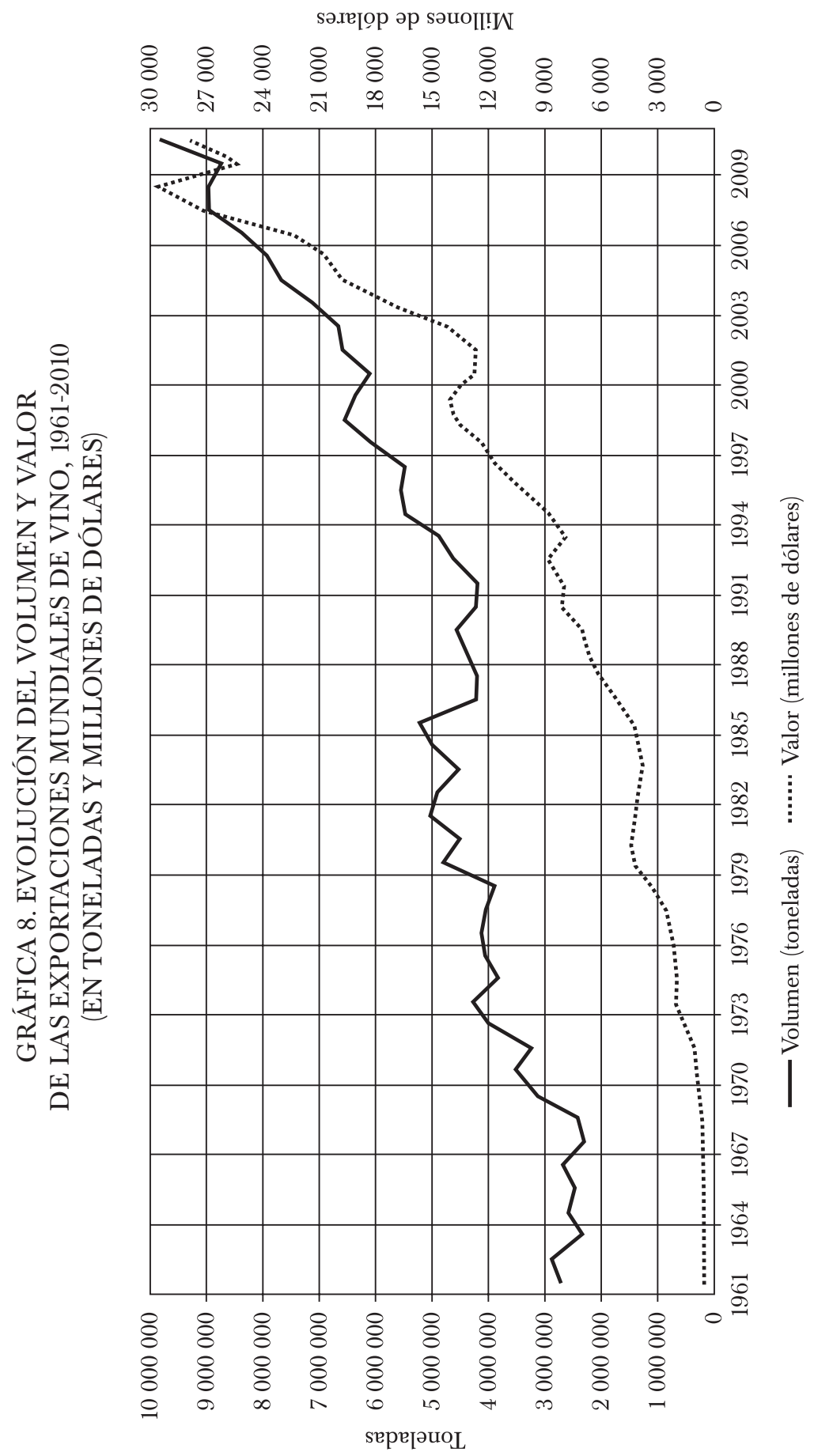

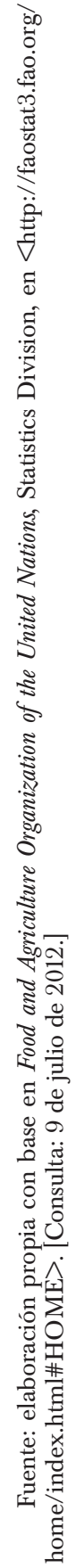


de la industria vitivinícola de las últimas décadas. No sólo se exporta más vino sino que la mayoría es de mejor calidad.

$\mathrm{El}$ incremento de las exportaciones mundiales se ha producido en una etapa de creciente dinamismo protagonizado por los agentes del Nuevo Mundo y de grandes desafíos para los del Viejo Mundo (véase gráfica 9), que tuvieron que afrontar la competitividad de los primeros. En general, la mayoría de los países explotaron más eficientemente las nuevas técnicas de cultivo y de producción masiva, y con una mayor dimensión empresarial y fuerte inversión publicitaria tensionaron el mercado internacional, que se hizo más competitivo ante un retroceso del consumo en la Europa mediterránea desde la década de 1980. Las exportaciones constituyen ahora un capítulo decisivo en la oferta de los países vitivinícolas, sean nuevos o viejos productores. Las exportaciones de los países del Nuevo Mundo han pasado de representar $2 \%$ de su producción de vino en la segunda mitad de la década de los años ochenta a más de $34 \%$ en la segunda mitad de la primera década del siglo XXI. En el mismo periodo, los del Viejo Mundo han pasado de 19.2 a 34.3\%. Los cambios han sido importantes incluso dentro de cada grupo. Entre los mediterráneos descuellan España y Portugal, cuyo empuje exportador contrasta con la desaceleración de los vinos franceses. En el hemisferio sur, el creciente peso de las exportaciones en las respectivas industrias vinícolas nacionales ha sido generalizado, sobresale el extraordinario dinamismo de los vinos chilenos y australianos cuyo peso relativo en la producción de 1980-1984 y 2005-2009 pasó de representar 23 y $2 \%$ a 65.3 y $61 \%$ respectivamente.

El cambio cuantitativo y cualitativo del sector vitivinícola ha sido muy intenso con la reciente globalización, ha beneficiado sobre todo a los países del hemisferio sur a partir de mediados de la década de 1990 (véanse gráficas 10 y 11). Los vinos latinoamericanos protagonizaron un fuerte empuje en los mercados internacionales, donde los argentinos y los chilenos fueron los vinos mejor aceptados, como a continuación se muestra.

\section{La mejora de la posición competitiva}

La mejora de la posición competitiva de las exportaciones ha sido un fenómeno general, pero ha sido especialmente intensa en el Nuevo Mundo. En el conjunto de las exportaciones mundiales de vinos, sus ventas externas evolucionaron de 1.3 a $29.7 \%$ entre 1961 y 1965 y $2000-2010 .{ }^{27}$ Este incremento debe enmarcarse en un contexto global de crecimiento del comercio internacional de materias primas agrarias y productos alimenta-

\footnotetext{
${ }^{27}$ Anderson y Nelgen, Global, 2011, pp. 190-191.
} 


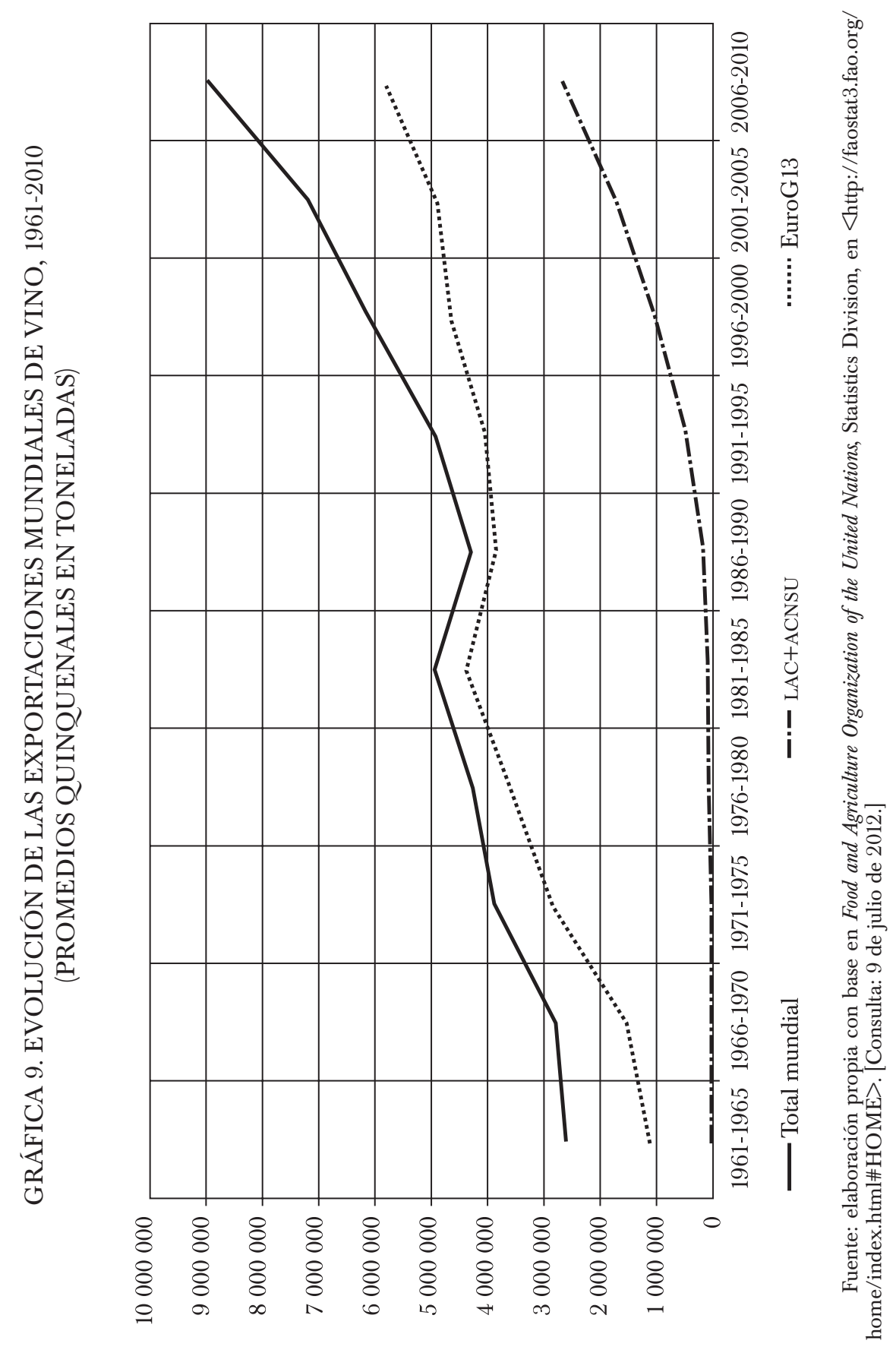




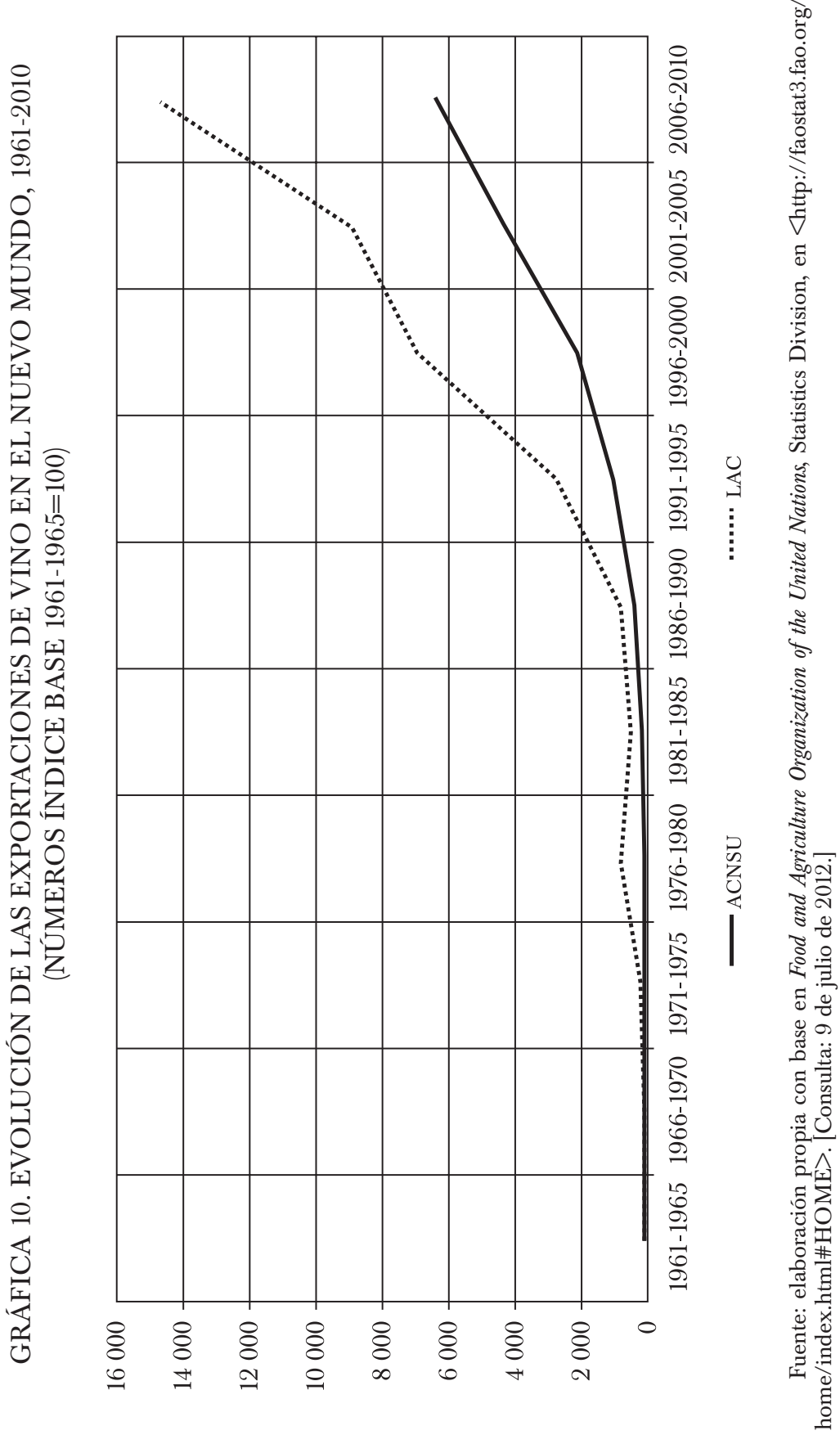



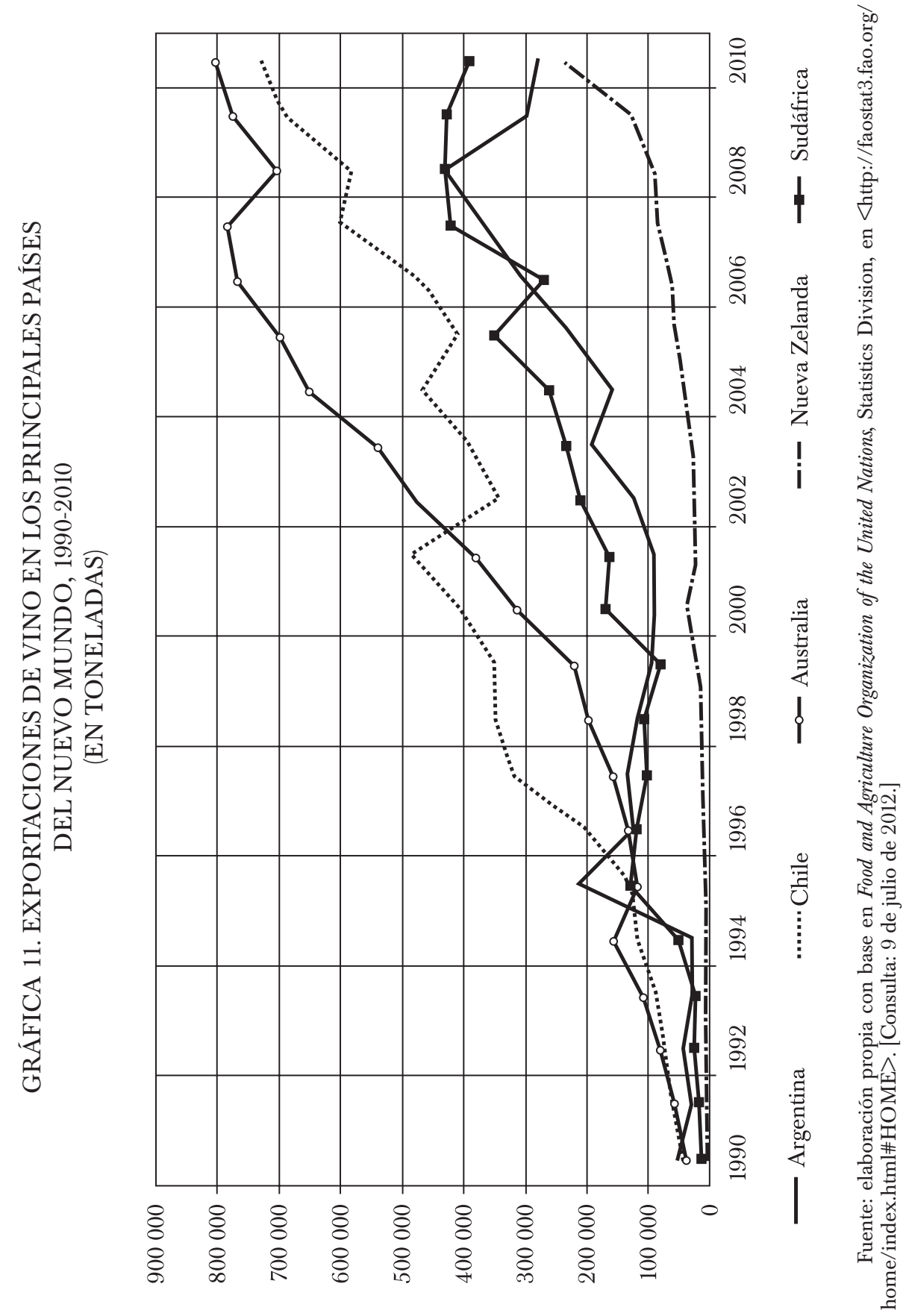
rios, favorecido por el crecimiento económico mundial, la liberalización del comercio internacional, la mejora en transportes y comunicaciones, la estabilidad en el sistema de cambio y la eliminación de barreras arancelarias en el caso europeo. ${ }^{28}$

En la década de 1990 se produjo una verdadera atracción por el vino que provocó casi una auténtica revolución enológica en muchas regiones del planeta y aumentó el protagonismo de los países del Nuevo Mundo en el mercado mundial. Los vinos de Estados Unidos (básicamente California), Chile, Argentina, Sudáfrica o Australia despertaron el interés de los mercados internacionales desde mediados de la década de 1980, pero fue en la década siguiente cuando sus exportaciones exhibieron un mayor empuje. Casi todos los países llegaron a ser competitivos en calidad y precio, apoyados principalmente en estrategias de publicidad realizadas por grandes distribuidoras mundiales. ${ }^{29}$ Basados en ese modelo empresarial, Estados Unidos y Australia alcanzaron las mayores cuotas de participación en el mercado mundial y también las tasas más elevadas de crecimiento entre 1990 y 1994. Los vinos de Chile, Argentina y Sudáfrica irrumpieron algo más tarde pero consolidaron posiciones destacadas por ese orden hacia finales del siglo Xx (véase cuadro 2). ${ }^{30}$

La globalización otorgó una primera ventaja a los países anglosajones y más tarde a los latinoamericanos. En las últimas décadas Australia pasó a ser el país más dinámico, siguiéndolo Chile. En ambos casos su participación dobló la cuota que mantenía el conjunto de los países del Nuevo Mundo, y su posición competitiva fue especialmente significativa en los mercados europeos más expansivos. Dada la buena relación calidad-precio y la diferenciación de precios respecto a los vinos producidos en los países mediterráneos, los vinos australianos aumentaron su cuota de mercado en Gran Bretaña en detrimento de los vinos franceses, y los caldos chilenos hicieran lo propio en el norte europeo. ${ }^{31}$ Los caldos argentinos calaron más profundamente en el mercado estadunidense, cuyas ventas a Canadá y Estados Unidos se multiplicaron por seis entre 2004 y 2010 y pasaron rápidamente de la nada despreciable cuota de $30.3 \%$ a repre-

${ }^{28}$ Langreo, "Sistema”, 2008; Aparicio, Pinilla y Serrano, "Europe”, 2009, y Serrano y Pinilla, "Causes", 2010, y "Evolution", 2011.

${ }^{29}$ Véanse Aylward, "Documentary", 2003; Cambolle y Giraud-Héraud, "Economic", 2003; Folwell y Volanti, "Changing", 2003; Geraci, "Fermenting", 2004; Gokcekus y Fargnoli, "Globalization", 2007; Green, Rodríguez y Seabra, "Empresas", 2003; Green, Rodríguez y Pierbattisti, "Global", 2003; Jordan, Zidda y Lockshin, "Australian", 2007; Jenster el al., Business, 2008; Langreo, "Mercados", 2002; Mora y Castaing, "Buenas", 2006, y Remaud, Beaujanot y Coudert, "Wine", 2006.

${ }^{30}$ Sobre los vinos de Sudáfrica, véase Esterhuizen y Rooyen, "Inquiry”, 2006.

${ }^{31}$ Steiner, "French", 2004, y "Australian", 2004; Barco, Navarro y Langreo, "Cambios", 2005, y Campbell y Guibert, "Old”, 2006. 


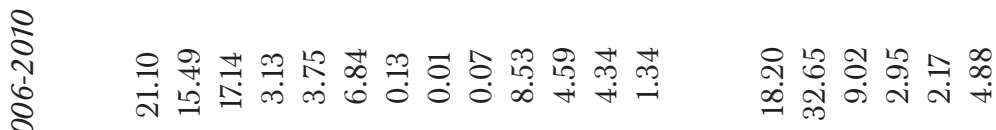

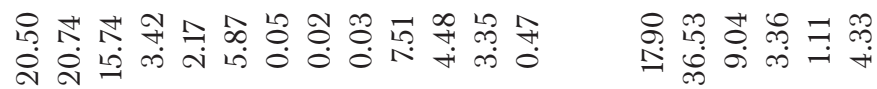

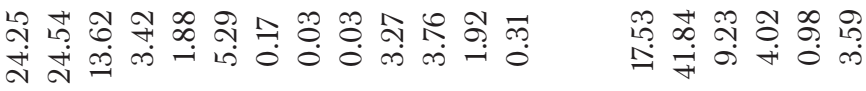

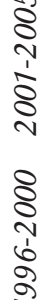

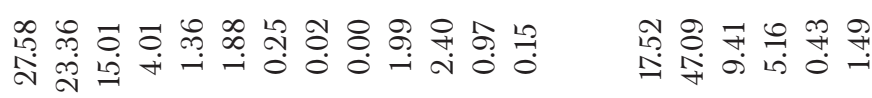

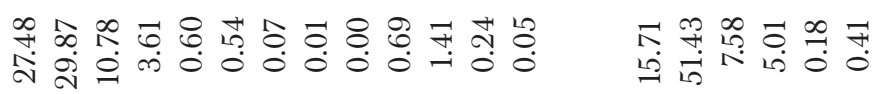

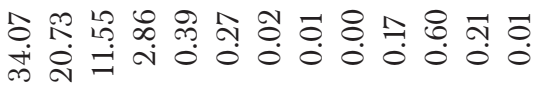

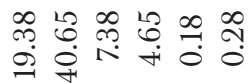

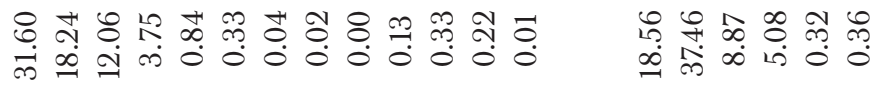

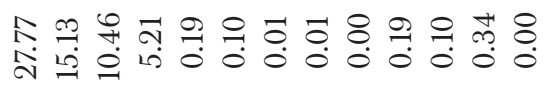

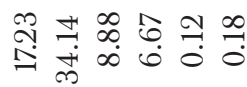

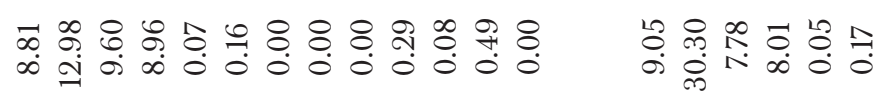

营

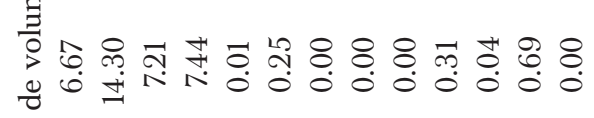

营

范

य

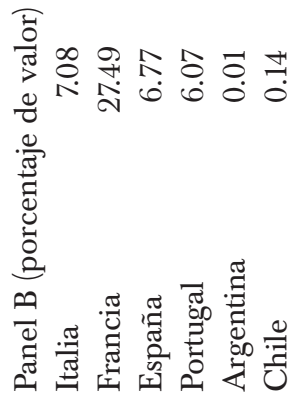




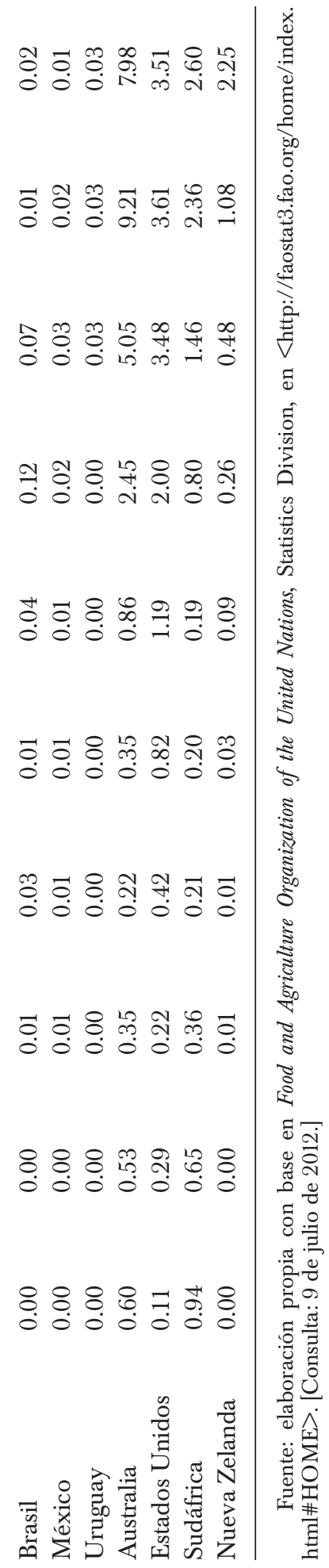


sentar 48.5\% respectivamente, en detrimento de la cuota relativa de vinos exportados a Gran Bretaña, Alemania y otros destinos. ${ }^{32}$

El posicionamiento en precios ha sido notorio en los países del Nuevo Mundo. Australia, Chile, Estados Unidos y Sudáfrica mostraron precios relativamente altos hasta la década de 1990. Desde entonces han experimentado un crecimiento más moderado pese al aumento considerable de sus ventas externas, mantienen precios competitivos y mejoran su cuota de mercado, principalmente en Europa, apoyados por agresivas políticas de marketing y precios similares a los europeos. Al no tener una excesiva regulación institucional, como existe con las DO y DOC en el marco europeo, disponen de ciertas ventajas: el producto se ofrece según variedades (monovarietales, principalmente) y no por lugares de procedencia, lo que hace mucho más sencilla la elección para el consumidor experto en vinos. Francia, entre los viejos productores, y Australia, entre los nuevos, presentan los precios relativamente más elevados. España se sitúa junto a Argentina entre los países con precios relativamente más reducidos, pudiendo hacer frente así a los mercados con productos de calidad y precios asequibles.

Los bajos precios que presentan los vinos de Argentina han sido un factor decisivo en su competitividad. Calificado como el gigante dormido del hemisferio sur, despertó bruscamente cuando abandonó su paridad con el dólar estadunidense y devaluó su divisa en dos tercios a finales de 2001. Desde entonces la proporción de vinos argentinos exportados aumentó de 4 a 29\% para el año $2008 .^{33}$ Inicialmente la calidad de esas exportaciones fue baja, pero ha estado creciendo rápidamente: su valor unitario casi se triplicó entre 2003 y 2010, pasando de 0.88 a 2.67 dólares por litro, y redujo a la mitad la proporción de granel en el total de las exportaciones, pasando de 52 a $26 \% .^{34}$ Ello contrasta con la tendencia creciente de la participación del vino a granel en las exportaciones de Australia, Nueva Zelanda y Estados Unidos que casi se han cuadruplicado entre 1999 y $2010 .^{35}$ Las recientes exportaciones del Nuevo Mundo en su conjunto suponen un porcentaje ligeramente mayor en volumen que la UE- $15,{ }^{36}$ en contraste con lo ocurrido hace más de una década, cuando la cuota del Nuevo Mundo era la mitad de la del Viejo Mundo. Esta situación

${ }^{32}$ Defrancesco, Estrella y Gennari, "Would”, 2012 y Mariani, Pomarici y Boatto, "International", 2012, p. 33.

${ }^{33}$ Anderson y Nelgen, Global, 2011, p. 83.

${ }^{34}$ Ibid., pp. 73 y 111.

${ }^{35}$ Ibid., p. 73.

${ }^{36}$ Con la incorporación a la Unión Europea de Austria, Finlandia y Suecia el 1 de enero de 1995 se configuró la denominada UE-15, junto a los anteriores Estados miembros: Alemania, Bélgica, Dinamarca, España, Francia, Grecia, Irlanda, Italia, Luxemburgo, Países Bajos, Portugal y el Reino Unido. Esto supuso que las instituciones europeas integraran casi en su totalidad a los países de Europa Occidental. Dicha situación estuvo vigente hasta el 1 de mayo de 2004, ya que 
reflejaría la importancia que adquiere el embotellado de vinos baratos en destino para la mayor parte de las grandes empresas, además de la saturación de la oferta en Australia y Nueva Zelanda. ${ }^{37}$

\section{EL ÍNDICE DE VENTAJA COMPARATIVA REVELADA (VCR)}

Desde 1980 se vienen produciendo importantes cambios en los modelos de consumo. Una serie de países de escasa tradición vinícola y de regiones no productoras del mundo demandan vinos de calidad que abastecen los países del Nuevo Mundo. ${ }^{38}$ En general, estos países han incrementado las exportaciones de vino de gama media a precios económicos, lo cual ha favorecido el aumento de su posición competitiva en el comercio internacional. Los vinos australianos y chilenos muestran una mejor posición en los mercados. A escala global, eran invisibles en la década de 1960: apenas exhibían cuotas de $1 \%$ a finales de la década de 1980 y una década más tarde las multiplicaron casi por diez hasta alcanzar los índices más altos de especialización. $^{39}$

Con el fin de comprobar la competitividad de los vinos de diferentes países en el mercado global empleamos el índice de ventaja comparativa revelada (VCR) o índice de Balassa. ${ }^{40}$ Este índice es utilizado habitualmente en los estudios de comercio internacional ${ }^{41}$ y se define como el cociente entre la participación de un producto en las exportaciones de un país y la participación de ese mismo producto en las exportaciones mundiales. ${ }^{42} \mathrm{El}$ economista Bela Balassa acuñó el término de "índice de ventaja comparativa revelada" (VCR) con el fin de indicar que las ventajas comparativas entre naciones pueden ser reveladas por el flujo del comercio de mercancías, puesto que el intercambio real de bienes refleja los costos relativos y

la incorporación de diez nuevos países miembros de la Europa del este supuso la conformación de la denominada UE-25.

${ }^{37}$ Anderson y Nelgen, Global, 2011, p. 73.

${ }^{38}$ Banks y Overton, "Old", 2010.

${ }^{39}$ Para los vinos australianos, Osmond y Anderson, Trends, 1998.

${ }^{40}$ Balassa, "Changing", 1979, y Comparative, 1989.

${ }^{41}$ Son numerosos los estudios que miden la competitividad de las exportaciones de vino a partir de este índice; para el caso chileno, véanse Cerda et al., "Determinantes", 2008; Boriraj, "Analysing", 2008, y Esterhuizen y Rooyen, "Inquiry", 2006.

${ }^{42}$ El índice contempla la participación mundial de un determinado país en el comercio total de mercancías, en el bien analizado y en el resto de mercancías, al mismo tiempo que incluye los mismos parámetros para el resto del mundo. Por tanto, ofrece información de cómo los productores de un bien específico compiten a escala doméstica con otros productores de bienes por los recursos disponibles, al mismo tiempo que muestra la capacidad del país para competir en el mercado internacional de dicho bien específico. 
también las diferencias que existen entre los países, no necesariamente por factores de mercado. Su cálculo es:

$$
\operatorname{VCR}_{\mathrm{a}}^{\mathrm{i}}=\operatorname{VCE}_{\mathrm{a}}^{\mathrm{i}}-\operatorname{VCI}_{\mathrm{a}}^{\mathrm{i}}
$$

donde VCE es la ventaja comparativa revelada de las exportaciones de un país i, y donde VCI es la ventaja comparativa revelada de sus importaciones. Las fórmulas de cálculo son:

$$
\begin{gathered}
\operatorname{VCE}_{a}^{i}=\ln \left[\left(\mathrm{X}_{a}^{i} / \mathrm{X}_{n}^{i}\right) /\left(\mathrm{X}_{a}^{r} / \mathrm{X}_{n}^{r}\right)\right] \\
\operatorname{VCI}_{a}^{i}=\ln \left[\left(\mathrm{M}_{a}^{i} / \mathrm{M}_{n}^{i}\right) /\left(\mathrm{M}_{a}^{r} / \mathrm{M}_{n}^{r}\right)\right]
\end{gathered}
$$

donde $\mathrm{X}$ son las exportaciones, $\mathrm{M}$ las importaciones, $i$ el país, $a$ el producto, $r$ se refiere al mundo menos el país en análisis y $n$ se refiere al comercio de todas las mercancías menos el bien analizado. El índice VCR puede ser mayor o menor a cero. $\mathrm{Si}$ es mayor a cero, el producto es competitivo en el mercado internacional, pero si es menor a cero, el producto no es competitivo. Sin embargo, si es menor a cero no quiere decir que el país no tenga potencial competitivo en ese producto, sino que simplemente no ha desarrollado las ventajas comparativas para dicho producto. Si el índice para un país es mayor (menor) al de otro país, quiere decir que la nación con el índice más alto (bajo) está más (menos) especializada en el comercio de un determinado producto. Si el índice aumenta (disminuye) con el tiempo, el crecimiento del comercio del producto seleccionado es mayor (menor o negativo) en términos relativos al resto de las mercancías y respecto al resto del mundo (véase cuadro 3).

Los resultados muestran que los países exportadores del Viejo Mundo mantienen sus ventajas comparativas en el mercado mundial de vinos, lo cual les permite afrontar los desafíos de la creciente globalización. Sin embargo, la competitividad de las exportaciones (VCE) del Nuevo Mundo protagoniza un importante avance desde mediados de la década de 1980. Las exportaciones de Nueva Zelanda, Chile y Australia presentan los mejores índices, los siguen Argentina y Sudáfrica que muestran similares valores, siendo en conjunto índices positivos y casi muy cercanos a los de los exportadores del Viejo Mundo. Chile despunta significativamente al comienzo del periodo, y tras una ligera disminución en el segundo quinquenio de la década de 1970 presenta los mejores índices en los últimos tiempos, justo en los de mayor competencia (véanse gráficas 12 y 13 ).$^{43}$

Una mirada más atenta a la evolución de los últimos años pone de manifiesto que los grandes países productores han vuelto a aumentar sus

${ }^{43}$ Sobre el caso de Chile, véase Cerda et al., "Determinantes”, 2008. 


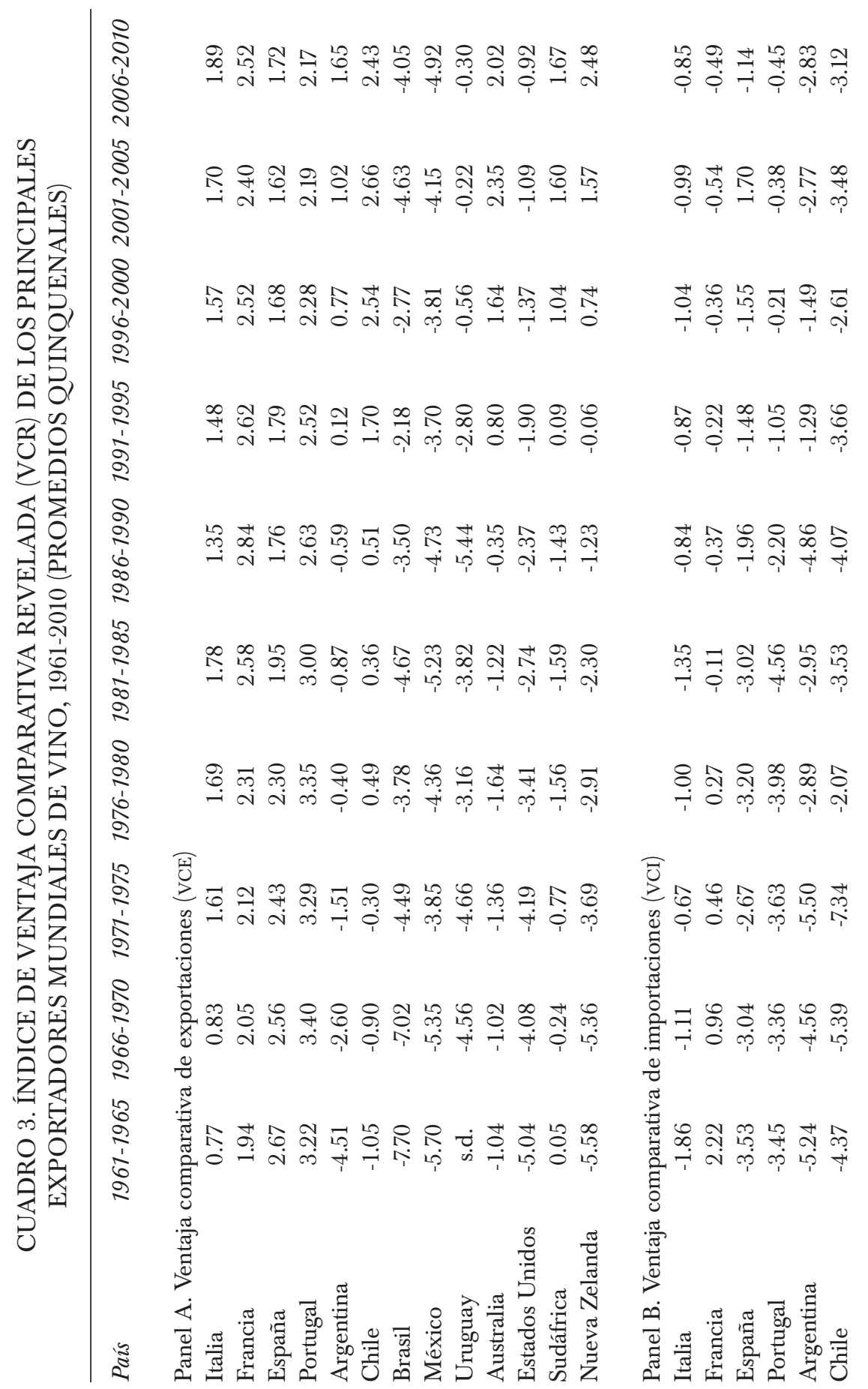




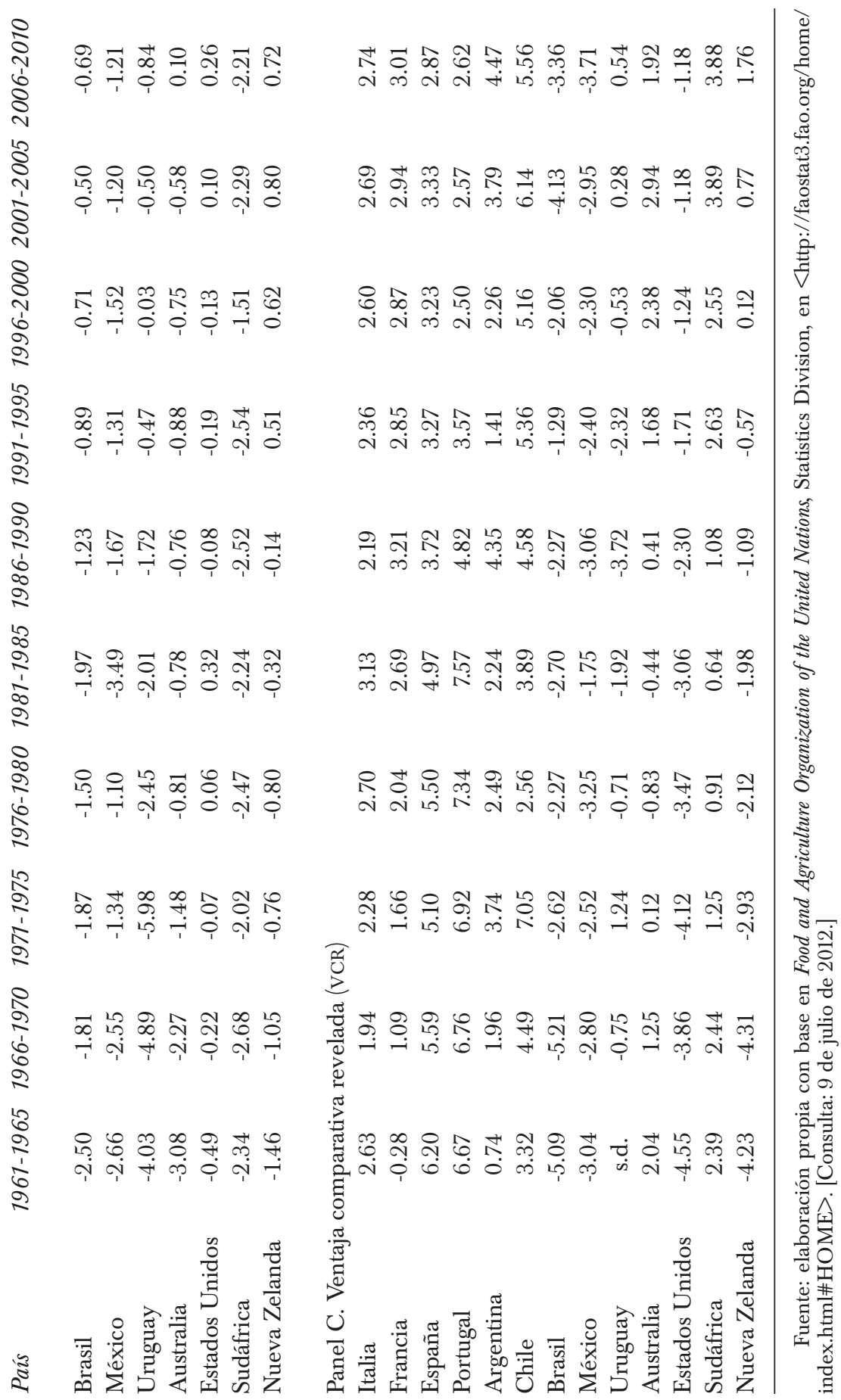




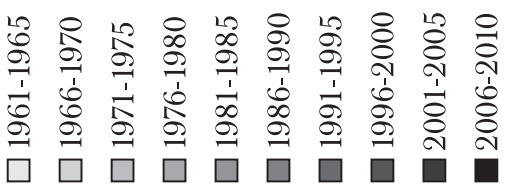

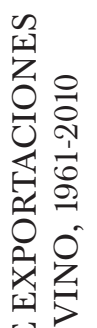

됨됨

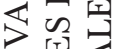

是起至

选卷

卷㐘光

$\checkmark$ ڤ

岩秃

䒠氮会

过是

됨 包

되르

0

艺包

는 되

艺到

5

志

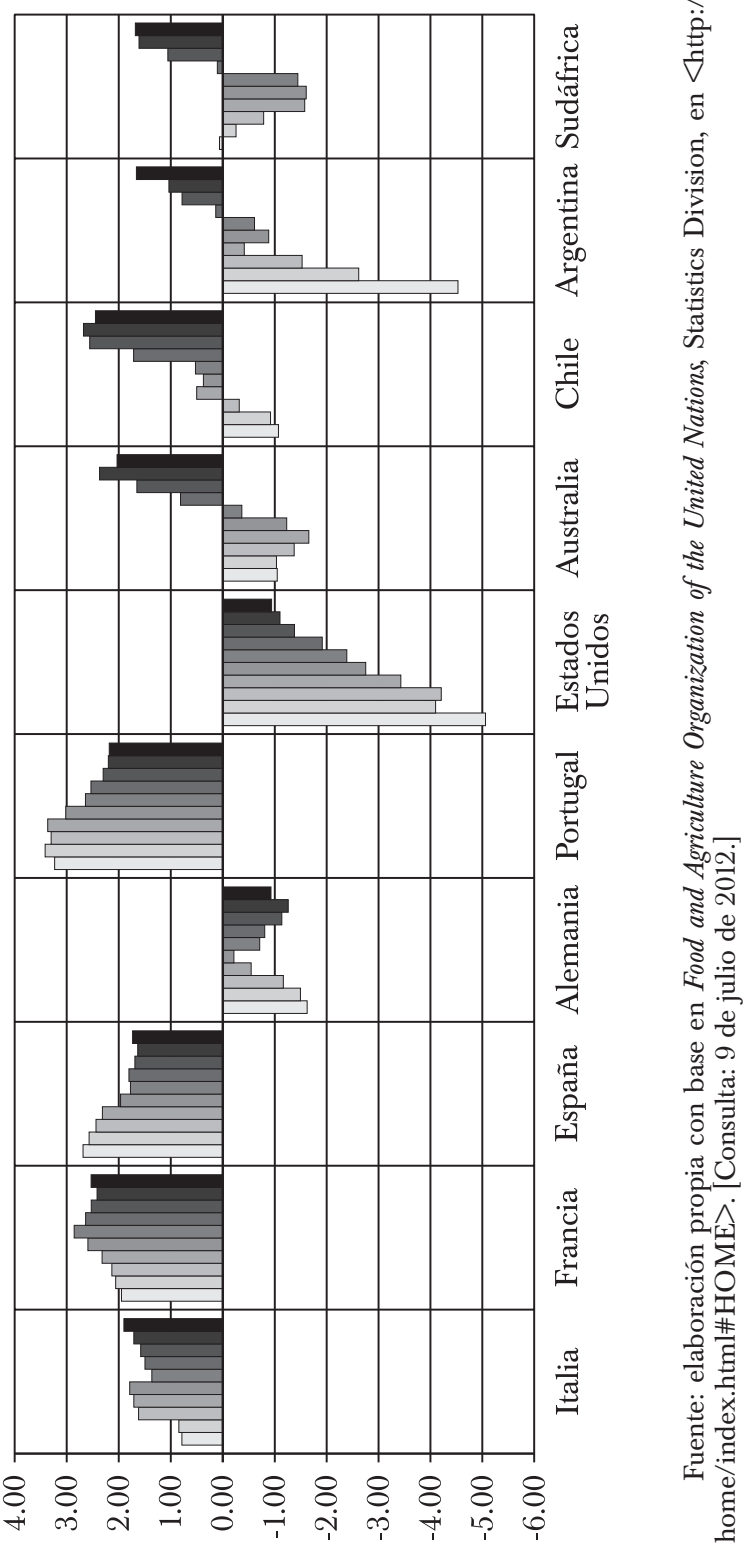



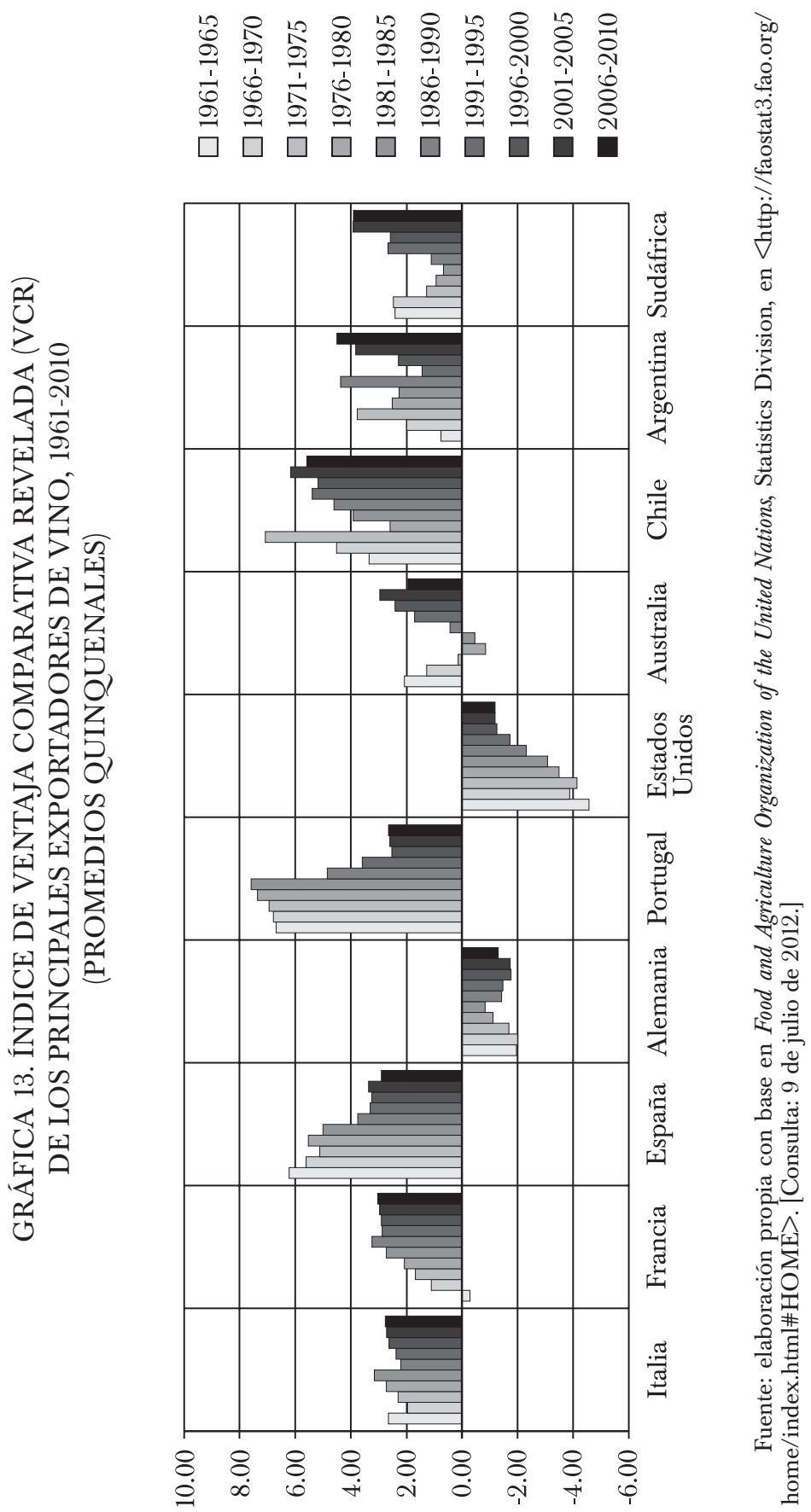
exportaciones y ganan posiciones relativas en el mercado global del vino. En buena medida ha sido producto de la estrategia dirigida a los consumidores del norte de Europa, Norteamérica, China y Oriente Medio. Su objetivo ha sido conseguir productos con una calidad-precio más atractivos para el consumidor. El caso de los vinos argentinos es ejemplar en los últimos tiempos, coincidiendo con los cambios producidos por los consumidores a raíz de la crisis económica mundial de $2008 .{ }^{44}$

Desde mediados de la década de 1990, de acuerdo con los resultados de los índices VCE y VCR, los países vitivinícolas mediterráneos mantienen su competitividad con el fuerte crecimiento de las exportaciones sobre todo en la primera década del nuevo milenio. Sobresale el aumento del VCR francés por la mejora de su competitividad externa y la reducción de sus importaciones. Pero también descuellan los casos de España y Portugal que han visto que su ventaja comparativa se redujo hasta alcanzar los niveles del resto de los países de su área ${ }^{45} \mathrm{El}$ caso de las exportaciones españolas ha sido destacable en los últimos años y sobre todo en $2011{ }^{46}$ Sin embargo, los nuevos productores vitivinícolas han visto crecer considerablemente sus índices de ventaja comparativa en el mercado mundial. El hecho no está asociado a lo cerrado de sus mercados como ocurrió en décadas previas (con ventaja comparativa de importaciones en valores altamente negativos), sino a la mejora de la competitividad vía precio de sus exportaciones. El VCE de estos países ha crecido considerablemente en las dos últimas décadas hasta alcanzar el nivel de los países tradicionales del Viejo Mundo (véase cuadro 2). De los países latinoamericanos, los vinos de Argentina y Chile son claros exponentes (véase gráfica 12).

Es sabido que la producción de vinos de calidad a precios competitivos ha sido la principal estrategia de las firmas empresariales del Nuevo Mundo. La exportación de vinos económicos de calidad sigue siendo una de las principales bazas de los nuevos productores, que ahora también se desarrolla entre los viejos productores. ${ }^{47}$ Pero a diferencia del Viejo Mundo, la ventaja competitiva de los nuevos países vitivinicultores reside en el desarrollo de entramados empresariales con estrategias corporativas de

${ }^{44}$ Entrevista a Federico Castellucci, director general de la OIV, Revista Digital Industria Vinícola, 1 de julio de 2011, en <http://www.interempresas.net/Vitivinicola/Articulos/54104-Entrevistaa-Federico-Castellucci-director-general-de-la-OIV.html>. [Consulta: 10 de julio de 2012.]

${ }^{45}$ Se ha de tener en cuenta que en la década de 1960 el VCR de estos países era tan elevado por lo reducido del total de sus exportaciones y por la importancia que el vino y los productos agrarios en general tenían en el conjunto de las ventas externas del país.

${ }^{46}$ Un estudio detallado en Martínez-Carrión y Medina-Albaladejo, "Change”, 2010, y “Competitividad", 2013.

${ }^{47}$ Es el caso de España, que tradicionalmente apostó por vinos de baja calidad y recientemente desarrolla una interesante especialización en vinos económicos de calidad, véanse Fernández, "Especialización”, 2012, y Martínez-Carrión y Medina-Albaladejo, “Competitividad”, 2013. 
integración vertical, empresas partícipes en todo el proceso productivo (con viñedos, plantas embotelladoras y de almacenaje) y en gran parte del proceso de distribución y comercialización para los principales mercados. Se trata de firmas con marcas fuertes, con una gama de productos relativamente homogéneos, que han podido realizar importantes inversiones en viñedos y en técnicas de producción orientadas incluso a la elaboración de vinos premium y superiores, competitivas en distintos segmentos y que afianzan su posición internacional en los mercados más jóvenes y dinámicos de Asia (China), Europa (Gran Bretaña, Alemania) y América (Estados Unidos, Canadá, incluso Brasil.$^{48}$

También es conocido que los grandes entramados empresariales y las multinacionales caracterizan a los países del hemisferio sur, pero no sólo a los anglosajones. En Argentina y Chile existe un importante tejido de empresas medianas de carácter nacional y destacan importantes empresas bodegueras con una enorme capacidad de producción y distribución. En buena parte, la creciente competitividad de los países vitivinícolas del Cono Sur se ampara en la fortaleza de las grandes wineries, que compiten en distintos segmentos por su amplia diversificación de mercados y variedades de cepas (cultivadas más allá de su propio territorio nacional), su alta capacidad de negociación sobre los proveedores y el hecho de disponer de redes de comercialización y distribución propias en mercados dinámicos y en expansión. ${ }^{49}$ Un ejemplo en Chile es la empresa Viña Concha y Toro S. A., fundada en 1883 y considerada en la actualidad como la marca de vinos más importante e internacional de América Latina por su estrategia global de fortalecimiento de marcas en el mercado internacional, sus grandes inversiones en viñedos y plantas de embotellado en Canadá y Sudáfrica, y su estrategia de distribución y comercialización propia en los principales mercados de destino, como por ejemplo a través de Concha y Toro UK Limited (para Reino Unido) o Cono Sur Europe Limited. ${ }^{50}$ Pese a este y otros ejemplos, como las bodegas argentinas Catena, Peñaflor (Trapiche) y Zuccardi, ${ }^{51}$ que demuestran que los gerentes de las bodegas del

${ }^{48}$ Wittwer, "Drought", 2008.

${ }^{49}$ Mora, "Países", 2004.

${ }^{50}$ En 2007, la firma Viña Concha y Toro figuró en octava posición en el ranking de competencia externa, con las principales empresas bodegueras exportadoras del mundo, tras tres estadunidenses, una australiana y tres francesas, Wigodski et al., "Caso", 2008, p. 10.

${ }^{51}$ Stein, "Saviors", 2008. Una prueba de la relevancia que adquieren las firmas bodegueras chilenas y argentinas en el mundo del vino es el reconocimiento que hace anualmente la Asociación Mundial de Escritores y Periodistas de Vinos y Licores (WAWWJ, siglas en inglés). En el último ranking de las 100 mejores bodegas del mundo dado a conocer en febrero de 2013 por la calidad de sus vinos, destacaban cuatro firmas chilenas: Viña Luis Felipe Edwards Ltda. (10), Viña Concha y Toro (24), Viña Casa Silva, S. A. (34) y Viña Cono Sur S. A. (57), y cuatro argentinas: Bodega Trapiche S. A. (5), BVA S. A. Santa Ana (58), Bodegas Santa Julia (70) y Bodega El Esteco, 
Cono Sur tienen altos niveles de capacitación, conocimiento de los mercados, habilidades en marketing y experiencia internacional, de todas formas persisten limitaciones, como el acceso a los recursos financieros para la expansión del mercado y problemas en infraestructura del conocimiento o la distribución. ${ }^{52}$

\section{COnClusiones}

En este trabajo se ha presentado una panorámica de los cambios producidos en el mercado global del vino, desde 1961 a 2010, con particular atención a la evolución de la competitividad en los países latinoamericanos del hemisferio sur. Tras señalar la evolución de la superficie de viñedo, de los rendimientos y de la producción de vino, a escala mundial y por bloques de países diferenciando el Viejo y el Nuevo Mundo, destaca la competitividad de las exportaciones de los nuevos países productores durante la denominada segunda era de la globalización, justo cuando se conforma un mercado global de vinos.

Los cambios se han sustentado en importantes factores. Por un lado, destacan las estrategias productivas y comerciales de precios bajos y políticas vitivinícolas más flexibles que las impuestas en la Europa mediterránea o del Viejo Mundo. La modificación de ventajas comparativas, cambiantes en las dos últimas décadas del siglo Xx, ha supuesto un auténtico desafío para las exportaciones de los países del Nuevo Mundo. Por otro, el nuevo escenario se ha producido ante cambios sustanciales en las pautas de consumo de bebidas. La caída sostenida del consumo de vinos en los países de mayor tradición vitivinícola ha podido atenuarse por el incremento del consumo en países no consumidores y la demanda de los países emergentes, que hoy por hoy muestran un mayor dinamismo económico. Finalmente, en el caso de Europa no deben despreciarse los cambios en las políticas agrarias y normativas promovidas por la OCM, reguladoras del comercio y de la producción de vinos, que han influido sobre la oferta promoviendo su adaptación a las nuevas condiciones del consumo.

Para comprobar las cambiantes ventajas comparativas del comercio exterior hemos recurrido al índice VCR o de Balassa, ampliamente difun-

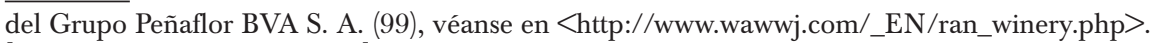
[Consulta: 15 de julio de 2013.]

${ }^{52}$ Kunc y Bas, "Innovation", 2009, y Wickramasekera y Bianchi, "Management", 2013. Bianchi y Wickramasekera, "Exploratory", 2013. Recientes estudios señalan también la necesidad de proteger las indicaciones geográficas, cuyo reconocimiento por los países del Cono Sur tendría efectos positivos sobre los consumidores dispuestos a pagar mejores precios por los atributos del vino, Defrancesco, Estrella y Gennari, "Would”, 2012. 
dido en este tipo de estudios. Entre las principales conclusiones se destaca que la ventaja comparativa de las exportaciones de Nueva Zelanda, Chile y Australia muestra los mejores resultados, siguiéndolos la de las exportaciones de vinos de Argentina y Sudáfrica. Las ventajas comparativas reveladas más favorables por sus mayores índices positivos se encuentran en los vinos de Chile y Argentina, a cierta distancia del resto de los más competitivos, tanto del Nuevo como del Viejo Mundo. El crecimiento de las exportaciones de vinos de calidad a precios económicos, muy por encima de las importaciones, la baja presencia de vinos a granel en comparación con otros países del hemisferio sur, y la flexibilidad de sus tipos de cambio, entre otros, explican la mejora de la ventaja comparativa revelada de Chile y Argentina en los últimos tiempos y, sobre todo, en la última década. El protagonismo de grandes empresas y cooperativas vitivinícolas ha sido fundamental en el Cono Sur, casi tanto como en los países anglosajones de la otra parte del hemisferio.

Los resultados animan a proseguir con estudios de caso sobre países y empresas para desvelar aspectos más detallados de la competitividad, tanto desde el lado de la oferta como de la demanda. Sería interesante conocer las estrategias cambiantes ante los nuevos desafíos que entraña el incremento de la competencia en el mercado global, y cómo afrontan las empresas exportadoras de vino las condiciones a que se ven sometidas en su país de origen: regulaciones, tipos de cambio, costos, subsidios, niveles inflacionarios, incidencia de los insumos importados, entre otras. Una prometedora línea de investigación sería explorar los procesos de internacionalización de las empresas bodegueras, pese a que el mercado interior ha sido decisivo hasta hace poco, y analizar los procesos de diferenciación que desarrollan para mejorar la competitividad en un mercado cada vez más globalizado. También convendría analizar los destinos de la oferta y las condiciones de los mercados de consumo, teniendo en cuenta el fuerte potencial de crecimiento de los nuevos países consumidores, como China, India, Rusia, Brasil y otros países con mercados emergentes, así como el papel que desempeñan las instituciones vitivinícolas o las políticas de promoción en el exterior.

\section{BiBLIOGRAFÍA}

Anderson, Kym, The World's Wine Markets. Globalization at Work, Cheltenham, Edward Elgar, 2004.

y Signe Nelgen, Global Wine Markets, 1961 to 2009: a Statistical Compendium, Adelaide, The University of Adelaide Press, 2011. 
Aparicio, Gema, Vicente Pinilla y Raúl Serrano, "Europe and the International Trade in Agricultural and Food Products, 1870-2000” en Pedro Lains y Vicente Pinilla (eds.), Agriculture and Economic Development in Europe since 1870, Londres y Nueva York, Routledge, 2009, pp. 52-75.

AYLWARD, DAVID K., "A Documentary of Innovation Support among New World Wine Industries", Journal of Wine Research, Routledge/Institute for Master of Wine, vol. 14, núm. 1, 2003, pp. 31-43.

Balassa, Bela, "The Changing Pattern of Comparative Advantage in Manufactured Goods", The Review of Economics and Statistics, MIT Press, vol. 61, núm. 2, mayo de 1979, pp. 259-266.

, Comparative Advantage, Trade Policy and Economic Development, Nueva York, New York University Press, 1989.

Banks, Glenn y John Overton, "Old World, New World, Third World? Reconceptualising the Worlds of Wine", Journal of Wine Research, Routledge/Institute for Master of Wine, vol. 21, núm. 1, 2010, pp. 57-75.

Barco, Emilio y Ma. Cruz Navarro, "Factores de cambio en el mercado internacional del vino en un escenario de crisis”, XIV Reunión Economía Mundial. Internacionalización en Tiempos de Crisis, Jaén, mayo-junio de 2012. y Alicia Langreo, "Cambios en el mercado internacional de vino. Algunas preguntas sobre el éxito del vino australiano”, Distribución y Consumo, Mercasa, núm. 80, marzo-abril de 2005, pp. 53-63.

Bianchi, Constanza y Rumintha Wickramasekera, "An Exploratory Study of the Factors Enhancing and Inhibiting Export Growth in the Chilean Wine Industry", Journal of International Food and Agribusiness Marketing, Routledge, vol. 25, núm. 2, 2013, pp. 85-102.

Bocco, Adriana y Daniela Dubbini, "Reestructuración productiva, regulaciones laborales y empleo en la vitivinicultura" en ANA MARÍA MATEU, Vinos y competitividad agroindustrial: un largo camino, Instituto de Ciencias Humanas Sociales y Ambientales/Universidad Nacional de Cuyo, Mendoza, 2011, pp. 55-80.

BORIRAJ, JumPOTH, "Analysing and Modelling International Trade Patterns of the Australian Wine Industry in the World Wine Market", tesis de grado, Victoria University, 2008.

Cambolle, Claire y Eric Giraud-Héraud, "Economic Analysis of Certification by an aOC" en Silvia Gatti, Eric Giraud-Héraud y Samir Mili (eds.), Wine in the Old World. New Risks and Opportunities, Milán, Franco Angeli, 2003, pp. 15-28.

Campbell, Gwyn y Nathalie Guibert, "Old World Strategies against New World Competition in a Globalizing Wine Industry", British Food Journal, Emerald, vol. 108, núm. 4, 2006, pp. 233-242.

(eds.), Wine, Society and Globalization: Multidisciplinary Perspectives on the Wine Industry, Nueva York-Basingstoke, Palgrave Macmillan, 2007. 
Canning, Patrick y Agnes Perez, Economic Geography of the U.S. Wine Industry, Nueva York, American Association of Wine Economists, septiembre de 2008 (AAWE Working Paper, núm. 22).

Cerda, ArCAdio et al., "Determinantes de la competitividad de las exportaciones de vino chileno", Panorama Socioeconómico, Universidad de Talca, vol. 26, núm. 37, julio-diciembre de 2008, pp. 172-181.

Cerdá, Juan Manuel, Condiciones de vida y vitivinicultura. Mendoza, 1870-1950, Bernal, Universidad Nacional de Quilmes Editorial, 2011.

Defrancesco, Edi, Ma. Jimena Estrella Orrego y Alejandro Gennari, "Would New World Wines Benefit from Protected Geographical Indications in International Markets? The Case of Argentinean Malbec", Wine Economics and Policy, Elsevier, núm. 1, 2012, pp. 63-72.

Esterhuizen, Dirk y Johan VAn RoOYen, "An Inquiry into Factors Impacting on the Competitiveness of the South African Wine Industry", Agrekon, Routledge, vol. 45, núm. 4, diciembre de 2006, pp. 467-485.

estrella Orrego, Ma. Jimena, Edi Defrancesco y Alejandro Gennari, "The Wine Hedonic Price Models in the Old and New World: State of the Art", Revista de la Facultad de Ciencias Agrarias, Universidad Nacional de Cuyo, Mendoza, vol. 44, núm. 1, junio de 2012, pp. 205-220, en <http://www.scielo.org.ar/scielo.php?script=sci_arttext\&pid=S1853-86652012000100018\&lng=es\&nrm=iso $>$. [Consulta: 15 de julio de 2013.]

Fabre, Paula, La privatización de Bodegas y Viñedos Giol. Una experiencia exitosa, Buenos Aires, Comisión Económica para América Latina de las Naciones Unidas, 2005 (documento LC/BUE/R.263).

FERnÁNDEZ, EvA, "Especialización en baja calidad. España y el mercado internacional del vino, 1950-1990", Historia Agraria, Sociedad Española de Historia Agraria/ Universidad de Murcia, vol. 56, 2012, pp. 41-76.

Folwell, Raymond J. y Milko Volanti, "The Changing Market Structure of the USA Wine Industry", Journal of Wine Economics, American Association of Wine Economists/Cambridge University Press, vol. 4, núm. 1, 2003, pp. 25-30.

Gatti, Silvia, Eric Giraud-Hèraud y Samir Mili (eds.), Wine in the Old World. New Risks and Opportunities, Milán, Franco Angeli, 2003.

Gennari, Alejandro, Ma. Jimena Estrella Orrego y Leonardo Santoni, Wine Market Regulation in Argentina. Past and Future Impacts, Nueva York, American Association of Wine Economists, 2013 (AAWE Working Paper, núm. 136).

Geraci, Victor W., "Fermenting a Twenty-First Century California Wine Industry", Agricultural History, Agricultural History Society, vol. 78, núm. 4, otoño de 2004, pp. 438-465.

Giuliani, Elisa, Andrea Morrison y Roberta Rabelloti, Innovation and Technological Catch-Up. The Changing Geography of Wine Production, Cheltenham, Edward Elgar, 2011. 
Gokcekus, Omer y Andrew Fargnoli, "Is Globalization Good for Wine Drinkers in the United States?", Journal of Wine Economics, American Association of Wine Economists/Cambridge University Press, vol. 2, núm. 2, 2007, pp. 187-195.

Green, Raúl, Manuel Rodríguez Zúñiga y Alexandra Seabra Pinto, "Las empresas de vino de los países del Mediterráneo, frente a un mercado en transición", Distribución y Consumo, Mercasa, núm. 71, septiembre-octubre de 2003, pp. 77-93.

Green, Raúl, Manuel Rodríguez Zúñiga y Leandro Pierbattisti, "Global Market Changes and Business Behavior in the Wine Sector" en Silvia GatTi, ERIC Giraud-HÉraud y SAmir Mili (eds.), Wine in the Old World. New Risks and Opportunities, Milán, Franco Angeli, 2003, pp. 157-170.

Hannin, Hervé et al. (dirs.), La vigne et le vin. Mutations économiques en France et dans le monde, Francia, La Documentation Française, 2010 (Collection les Études de la Documentation Française).

Heijbroek, Arend, Changing Competitiveness in the Wine Industry. The Rise and Fall of Wine Countries, Utrecht, Rabobank, 2007.

International Organisation of Vine and Wine, Statistical Report on World Vitiviniculture, 2013, en <http://www.oiv.int/oiv/info/esstatsro?lang=es>. [Consulta: 15 de julio de 2013.]

Jenster, Per V. et al., The Business of Wine. A Global Perspective, Copenhage, Copenhagen Business School Press, 2008.

Jenster, Per V. y Yiting Cheng, "Dragon Wine: Developments in the Chinese Wine Industry”, International Journal of Wine Business Research, Emerald, vol. 20, núm. 3, 2008, pp. 244-259.

Jordan, Rohan, Pietro Zidda y Larry Lockshin, "Behind the Australian Wine Industry's Success: Does Environment Matter?", International Journal of Wine Business Research, Emerald, vol. 19, núm. 1, 2007, pp. 14-32.

Kunc, Martin y Tomas G. Bas, Innovation in the Chilean Wine Industry: the Impact of Foreign Direct Investments and Entrepreneurship on Competitiveness, Nueva York, American Association of Wine Economists, 2009 (AAWE Working Paper, num. 46).

Langreo-Navarro, Alicia, "Los mercados de vinos y las estrategias de las bodegas españolas", Distribución y Consumo, Mercasa, núm. 65, septiembre-octubre de 2002, pp. 36-45.

, "El sistema alimentario mundial. Principales tendencias y efectos sobre los sistemas alimentarios locales", Distribución y Consumo, Mercasa, núm. 100, julioagosto de 2008, pp. 258-274.

Mariani, Angela, Eugenio Pomarici y Vasco Boatto, "The International Wine Trade: Recent Trends and Critical Issues", Wine Economics and Policy, Elsevier, vol. 1, 2012, pp. 24-40.

Marks, Denton, "Competitiviness and the Market for Central and Eastern European Wines: A Cultural Good in the Global Wine Market”, Journal of Wine Research, Routledge/Institute for Master of Wine, vol. 22, núm. 3, 2011, pp. 245-263. 
Martínez-Carrión, José M. y Francisco J. Medina-Albaladejo, “Change and Development in the Spanish Wine Sector, 1950-2009”, Journal of Wine Research, Routledge/Institute for Master of Wine, vol. 21, núm. 1, 2010, pp. 77-95. "Las transformaciones del sector vitivinícola en España, 1960-2006" en Ana María Mateu, Vinos y competitividad agroindustrial: un largo camino, Mendoza, Instituto de Ciencias Humanas Sociales y Ambientales/Universidad Nacional de Cuyo, 2011, pp. 229-253.

"La competitividad internacional de la industria vinícola española durante la globalización del vino", Revista de Historia Industrial, Universitat de Barcelona, vol. 52, año XXII, núm. 2, 2013, pp. 139-174.

Mateu, Ana María y Steve Stein, El vino y sus revoluciones. Una antología histórica sobre el desarrollo de la industria vitícola argentina, Mendoza, Universidad Nacional de Cuyo, 2008.

Mora, CARlos, "Los países emergentes en el mercado mundial vitivinícola: el vino chileno, situación actual y perspectivas", Viticultura Enología Profesional, Agro Latino, núm. 92, 2004, pp. 5-26.

Mora, Pierre y Yohand Castaing, Buenas prácticas en marketing del vino. 20 estudios de casos de vinos del mundo, Madrid, Mundi/Prensa, 2006.

Morilla-Critz, José, "Cambios en las preferencias de los consumidores de vino y respuestas de los productores en los dos últimos siglos” en José CARMONA et al. (eds.), Viñas, bodegas y mercados. El cambio técnico en la vitivinicultura española, 18501936, Zaragoza, Prensas Universitarias de Zaragoza, 2001, pp. 13-38.

Oczkowski, Edward, "A Hedonic Price Function for Australian Premium Table Wine”, Australian Journal of Agricultural Economics, Wiley-Blackwell, núm. 38, 1994, pp. 93-110.

Osmond, Robert y Kym Anderson, Trends and Cycles in the Australian Wine Industry, 1850 to 2000, Adelaida, University of Adelaide, 1998.

PAN-Montojo, JuAn, "Las vitiviniculturas europeas: de la primera a la segunda globalización”, Mundo Agrario: Revista de Estudios Rurales, vol. 9, núm. 18, primer semestre de 2009, en < http://mundoagrario.unlp.edu.ar/article/view/v09n18a08/842>.

Parcero, Jorge Osiris y Emiliano Villanueva, World Wine Exports: What Determines the Success of New World Wine Producers?, Nueva York, American Association of Wine Economists, 2011 (AAWE Working Paper, núm. 87).

Perone, Jorge, Identidad o masificación: una encrucijada en la industria vitivinícola argentina, Mendoza, Universidad Nacional de Cuyo, 1985 (serie Estudios, sección Administración, núm. 25).

Remaud, Hervé, André Beaujanot y Jean-Pierre Couderc, "Wine Business Practices: a New Versus Old Wine World Perspective”, Agribusiness, Wiley, vol. 22, núm. 3, verano de 2006, pp. 405-416.

RichaRD-JORBA, RODOLFO et al., La región vitivinícola argentina. Transformaciones del territorio, la economía y la sociedad, 1870-1914, Bernal, Universidad Nacional de Quilmes, 2006. 
Segrelles Serrano, José Antonio, "La política agrícola común de la Unión Europea y la soberanía alimentaria de América Latina: una interrelación dialéctica”, Scripta Nova. Revista Electrónica de Geografía y Ciencias Sociales, vol. XVI, núm. 415, octubre de 2012, en <http://www.ub.es/geocrit/sn/sn-415.htm>.

Serrano, Raúl y Vicente Pinilla, "Causes of World Trade Growth in Agricultural and Food Products, 1951-2000: a Demand Function Approarch", Applied Economics, Routledge, vol. 42, núm. 27, noviembre de 2010, pp. 3503-3518.

, "The Evolution and Changing Geographical Structure of World Agri-food Trade, 1951-2000", Revista de Historia Industrial, Universitat de Barcelona, núm. 46, 2011, pp. 97-125.

Simpson, James, Creating Wine. The Emergence of a World Industry, 1840-1914, Princeton, Princeton University Press, 2011.

"Factor Endowments, Markets and Vertical Integration. The Development of Commercial Wine Production in Argentina, Australia and California, ca. 1870-1914", Revista de Historia Económica, Journal of Iberian and Latin American Economic History, Cambridge University Press, vol. 29, núm. 1, 2011, pp. 39-66.

Stein, Steve, “Our Saviors May not Speak Spanish; Changing Markets and Strategies in Argentina's Wine Revolution, 1990-2008”, Nueva York, American Association of Wine Economists, 2008 (AAWE Working Paper, núm. 21).

Steiner, Bodo E., "Australian Wines in the British Wine Market: a Hedonic Price Analysis", Agribusiness, Wiley, núm. 20, 2004, pp. 287-307.

, "French Wines on the Decline? Econometric Evidence from Britain", Journal of Agricultural Economics, Wiley, vol. 55, núm. 2, julio de 2004, pp. 267-288.

Thorpe, Michael, "The Globalisation of the Wine Industry: New World, Old World and China”, China Agricultural Economics Reviere, Emerald, vol. 1, núm. 3, 2009, pp. 301-313.

Wickramasekera, Rumintha y Constanza Bianchi, "Management Characteristics and the Decision to Internationalize: Exploration of Exporters vs. Non-Exporters within the Chilean Wine Industry", Journal of Wine Research, Routledge/Institute for Master of Wine, vol. 24, núm. 3, 2013, pp. 195-209.

Wigodski, Teodoro, Ariel Martínez Gavilán y René Andrés Sepúlveda lorca, “Caso: Viña Concha y Toro S. A. modelo de internacionalización”, Chile, Universidad de Chile, 2008 (Documento de Trabajo. Serie Gestión, núm. 106).

Wine Institute, Per Capita Wine Consumption by Country, 2010, en <http://www.wineinstitute.org/files/PerCapitaWineConsumptionCountries. pdf $>$.

World Wine Consumption by Volume, 2010, en <http://www.wineinstitute. org/files//WorldWine\%20ConsumptionbyVolume.pdf>.

WitTwer, Glyn, "Will Drought Erode the Competitiveness of Australia's Wine Industry?", General Paper num. G-173, Monash University, 2008.

ZAPATA, SANTIAGO, "La revolución vitivinícola y sus efectos sobre el negocio corchero”, Madrid, Asociación Española de Historia Económica, 2010 (Documentos de trabajo, núm. 1.002). 